TABLE OF CONTENTS

I. Introduction -

II. Methodology -_- 2

Selection of TATC Facilities _... 2

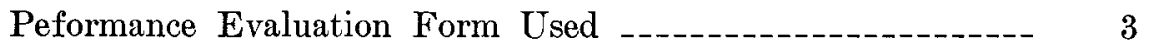

Performance Ratings by Supervisors, Crew Chiefs, and Peers -- 4

Rating the Relative Importance of Performance-Rating-Form

Items - -

Collection of Job Ratings and Other Data _-_-_-_-_-_--- 4

III. Results and Discussion

The Total Sample

Reliability of RLGR Ratings

Empirical Interrelationships of Age, Experience, and RLGR

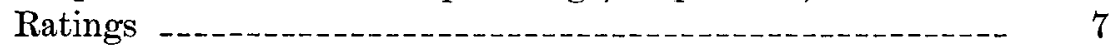

Means of RLGR Ratings by ATCS Age Group _........ 9

Means of RLGR Ratings by FAA ATC Experience Groupings - -

Interaction Effects of Age and Experience _............. 13

A. Performance of Dichotomized Age Groups by Experience Level -......... 13

B. Performance of Dichotomized Experience Groups by Age Level _....................... 13

C. Dominance of Aging Over Experience Effects ____ 16

Performance Evaluations Weighted in Terms of Item Import Ratings -

Facility Differences -

Correlative Data for Combined Facilities _._._._._._. 17

Comparison of Empirical Relationships by Facility _....... 17

Comparison of Results for High., Intermediate-, and LowRanked Facilities _._. 19

Quest for Explanations Why Few Older ATCSs Worked Within Highest-Ranked Facilities _._._. 23

A. Training-Entry Age _-_._. 23

B. Facility Transfers - 23

C. Mean Ratings by Age Level for ATCSs of the Three

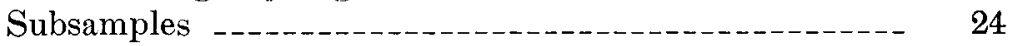

Findings for Combined Intermediate and Low Subsamples Only _- 25

IV. Summary and Conclusions _._. 26 



\section{THE RELATIONSHIPS OF AGE AND ATC EXPERIENCE TO JOB PERFORMANCE RATINGS OF TERMINAL AREA TRAFFIC CONTROLLERS}

\section{Introduction.}

Numerous studies ${ }^{2-4}{ }^{10-14}$ by the Civil Aeromedisal Institute (CAMI) during the past 13 years have been remarkably consistent in indicating chronological age at time of entry into Air Traffic Control Specialist (ATCS) training to be inversely related to measures of performance in the FAA Academy's basic ATC training courses and post-Academy attrition-retention status. Such itudies ${ }^{2} 101214$ have revealed that personnel unler 31 years of age who possessed little or no pre-FAA ATC-related experience, as well as former military controllers no older than 35 , were nuch more apt to succeed in ATCS training :han their older colleagues. Moreover, reearch $^{212-14}$ has repeatedly demonstrated that rainees over 35 years old also tend to score sigificantly lower than those of younger age on a vide variety of aptitude tests having validity :or prediction of training performance.

A matter of more crucial importance, however, oncerns the extent to which job performance at he journeyman ATCS level may be associated vith age. Findings relevant to this issue were irst reported in 1962 by Trites and Cobb ${ }^{12}$ for a itudy in which age at entry into training was ralidated against Academy training performance, nd also against experimentally derived ratings if job performance rendered one to five years fter Academy graduation. The authors conluded that the chances of an individual being onsidered a satisfactory controller are approxiaately one in five if he is 33 years of age or older pon entering training, whereas the chances are bout one in two if he is younger than $33 .{ }^{12}$ In 964, a similar study ${ }^{14}$ of several hundred addiional ATCS personnel yielded results indicating hat Academy graduates with training entry ages f 33 and over were much more likely, relative o younger personnel, to have their supervisors evaluate their job performance as "marginal," rather than "satisfactory." The majority of subjects involved in both these earlier investigations, however, had not advanced to journeyman-controller status by the time the experimental ratings were collected; no distinction was made in either study with respect to the subjects' General Schedule (GS) levels (i.e., pay grades), and the major findings were based on analyses in which the data for Air Route Traffic Control Center (ARTCC) personnel were combined with those collected for ATCSs at Terminal Area Traffic Control (TATC) facilities.

The findings obtained in the research mentioned above served to further augment the apprehensiveness of many FAA officials regarding the potential effects of aging upon the performance of journeymen-level ATCSs, particularly at high-traffic-volume facilities. Moreover, the rapidity with which aviation was expanding underlay the consensus that ATC work was becoming increasingly more "stressful" and thence provided a reasonable basis for suspecting that cumulative stress effects arising from lengthy service in active control work might be at least partially responsible for age-related differences in performance.

The need for a more definitive assessment of the interrelationships of age, experience, and ATCS performance led to a survey-type study ${ }^{1}$ in 1965 in which experimental ratings of job performance, tenure information, and other data were collected for over 500 journeymen radar controllers at four ARTCC facilities. The study yielded a number of important findings. A statistically significant inverse relationship was obtained between age and rating level. Mean group ratings for controllers over 40 years of age were significantly lower than those of younger groups. Length of FAA ATC experience, when 
considered independently of age, proved to be negligibly related to rating level. While no significant interaction effects of age and experience were discovered, consistent trends in the results were found indicating progressively higher mean ratings extending from the lesser to the more experienced groups of controllers who were less than 41 years of age. For ATCSs of age 41 and older, howerer, the mean ratings of the more experienced groups were lower, though not significantly lower, than those of the less experienced groups. Within every experience level, the ATCSs of age 40 and younger had higher mean ratings than the older controllers and the mean differences between the ratings of the dichotomized age groups were progressively larger from the moderate to the lengthy experience levels. Copies of the "Employee Appraisal Record" (EAR, FAA Form 3693) were made available for 300 of the 568 ATCSs involved in the study. Ratings based on Part IV of the instrument proved much less effective than the experimental ratings for purposes of individual differentiation. Although findings stemming from analyses in which the operationally derived ratings served as criteria were therefore not as definitive as those based on the experimental ratings, they were in general agreement with the latter.

The present report concerns an investigation wherein procedures, somewhat similar to those used in the 1965 study of journeymen ARTCC (or Center) controllers, were employed to determine the interrelationships of age, FAA ATC experience, and ratings of job performance for journeymen ATCSs engaged in Terminal Area Traffic Control at several high-traffic-density airports. The ratings of job performance, background information, and other data were collected in conjunction with a comprehensive study which also included an assessment of the controllers' attitudes and motivations regarding their work and job environment. Other research priorities, ${ }^{2-4}$ which arose shortly after completion of the data collection phase (in February 1969), precluded rapid progress in the processing and analysis of the diverse types of information obtained for the 614 subjects. The first ${ }^{8}$ of two anticipated reports on the study was published in July 1971. It focused upon describing the nature, incidence, and intensity of the controllers' work attitudes and the relationship of the latter to age, experience, and performance. However, most analyses concerning the potential effects of age and experience upon level of job performance were reserved for inclusion in the present report.

\section{Methodology.}

Various groups within the FAA participated in formulation of the overall research design and in the development and tryout of the performance evaluation scales and other data collection devices. The impetus for much of this support originated with the FAA Headquarters' Office of Air Traffic Service (A'TS), through which all aspects of the study were coordinated. However, the helpfulness of ATS officials extended far beyond providing coordinative support. They assisted in the planning of certain phases of the project, reviewed and helped revise preliminary forms of the questionnaires and rating devices, and selected the specific TATC facilities at which the controller personnel were evaluated. More importantly, five ATCSs on the staff of Headquarters' ATS were designated to visit $14 \mathrm{fa}$ cilities (of the 17 ultimately selected) for purposes of briefing the participants and collecting data. The sixth member of the date collection team, an ATCS from the Nationa Aviation Facilities Experimental Center (NA. FEC) who had earlier headed a team of NAFEC ATCSs in developing the initial version of th performance evaluation form, visited two facili ties. The remaining member of the survey team a CAMI researcher with no experience in ATC work, collected data at one facility only.

Selection of TATC Facilities. The selectio: of the facilities at which data were collected wa based on a number of considerations. First, ; was reasoned that if age and experience wer indeed inversely related to performance, the $r$ lationships would probably be more pronounce at high IFR-density airports than at those har ing either relatively low IFR operations or VF. traffic only. ATC officials and the principal it vestigators therefore concurred that the selectic of the facilities should be made from amor those which, at that time, were of Level-I: status (i.e., facilities having 100,000 or more IF operations annually).

Inasmuch as the controllers at three of $t$ ] four airports having the heaviest IFR traf 
loads had just recently participated in other FAA studies, ATS indicated that those three should be excluded from the proposed survey to preclude further disruption of those controllers' work schedules. Due to various reasons, it was also decided that each facility at which the IFR room was not located within or near the tower should be excluded from the study. Bivariate frequency distributions of age and experience of the controllers at each of the remaining LevelIII TATC facilities were next prepared and examined. (The distributions were obtained through analysis of ADP tape records, current as of January 1968, which FAA Headquarters provided.) Twenty facilities for which the ranges of age and experience appeared to offer the best potential for study of possible interaction effects were tentatively selected. Due to limited travel funds, however, no visits were made to three of the 20 .

During the fiscal year 1969 (a period approximately midway in which the ATCS ratings were sollected), the 17 selected facilities had a combined total of $3,774,576$ IFR operations; the range was from 111,731 at Indianapolis, Indiana, ;o 374,354 at the Atlanta, Georgia, Municipal Airport, and the overall average per facility was 222,033.

Performance Evaluation Form Used. The JAMI study of ARTCC personnel had shown, is mentioned earlier, that supervisory ratings of ITCS performance based on the EAR (FAA Form 3693) offered little potential for individual lifferentiation. The distribution of such ratings vas abnormal; less than one-half of one per cent if the ratings were in the lowest two of five ategories whereas the ratings received by the a ajority of the subjects on each of six "key esult areas" indicated that they "exceeded the ob requirements." Most other appraisal methds in use when the present study was being lanned were, like those at the time of the IRTCC study, designed primarily for remedial nd diagnostic purposes and/or were not uniform rom facility to facility. Moreover, the operaionally derived evaluations of performance were ot expressed in quantitative terms and were enerally not amenable to quantification. Thus, ee first major efforts in preparing for the curont study focused upon the development of exerimental procedures with which to obtain reable, subjective, quantitative ratings of job performance at the journeyman TATC ATCS level.

NAFEC ATCS personnel, instructors in the FAA Academy's basic TATC training course, CAMI researchers, and A'TS officials contributed toward development of the ATCS Performance Evaluation Form. The instrument, a copy of which appears as Appendix 1, embodied a sevenpoint rating scale and listed 29 elements, or aspects of performance for evaluation. The first section of the instrument dealt with the technical aspects of TATC work. It was developed, as mentioned earlier, by controller-oriented personnel. Several items in this section represented original formulations but some were very similar in content and wording to the "performance indicators" (i.e., appraisal standards) specified by the FAA in its procedures for the offcial semi-annual "Over-the-Shoulder Rating" ("OSR") of each ATCS. (The official OSR's were not included in the present study because they were not amenable to quantification.) Through -use of the rating scale, the subjects were rated on each item, or element, of the first section; first, with respect to Radar ( $R$ ) control and then, on the same items, with respect to Local (L) control.

Eight items, extracted from evaluation instruments previously developed and used by CAMI for experimental purposes only, comprised the next section of the rating form. The section was entitled "General Related Elements of ATCS Performance" and pertained to teamwork, tactfulness, interest and effort toward self-improvement, adaptability to changes in procedures and policies, and the like.

The rating scale for the eight " $G$ " (General) elements of performance was the same as for the " $R$ " and " $L$ " items. It consisted of seven categories: "inadequate," "marginal," "below average," "average (or good)," "very good," "excellent," and "outstanding." Printed instructions requested that the evaluator try to be realistic in his evaluations and, insofar as possible, rate the ATCS with respect to performance rendered during the busiest, or peak-traffic, periods. For analysis purposes, each rating reflecting "inadequate" performance was coded as "1," "marginal" as "2," and so forth, with "outstanding" being assigned a code of " 7. ."

The last section of the instrument consisted of a single item which read, "Use the scale below 
Visits to the facilities for collection of job performance ratings and other data were made during November 1968 through February 1969. The specific date on which the data were obtained for each ATCS was used in determining his chronological age and length of FAA ATC experience. Due to an error, information relat- ing to age and experience was not obtained for one individual and, as a consequence, several analyses were based on 613 cases rather than 614 .

Age was recorded in years, rounded to nearest birthday, whereas experience was recorded in months. The two youngest subjects were 27 years of age, the oldest was 64 , and the mean age

Table 1. Frequency distributions of chronological age and FAA ATC experience for 613 journeyman-level ATCSs of $17 \mathrm{high-IFR-traffic-density} \mathrm{TATC}$ facilities.

\begin{tabular}{|c|c|c|c|c|c|}
\hline \multicolumn{3}{|c|}{ Chronological Age } & \multicolumn{3}{|c|}{ FAA ATC Experience } \\
\hline $\begin{array}{c}\text { Age } \\
\text { (Years) }\end{array}$ & $\mathbf{N}$ & $\begin{array}{l}\text { Per Cent } \\
\text { of Total }\end{array}$ & $\begin{array}{c}\text { Exp. } \\
\text { (Months) }\end{array}$ & $\mathbf{N}$ & $\begin{array}{l}\text { Per Cent } \\
\text { of Total }\end{array}$ \\
\hline $\begin{array}{l}60 \&> \\
59\end{array}$ & 1 & .16 & $\begin{array}{l}252 \&> \\
246-251\end{array}$ & $\begin{array}{r}13 \\
3\end{array}$ & $\begin{array}{r}2.12 \\
.49\end{array}$ \\
\hline 58 & 2 & .33 & $240-245$ & 1 & .16 \\
\hline $\begin{array}{l}57 \\
56\end{array}$ & 1 & .16 & $\begin{array}{l}234-239 \\
228-233\end{array}$ & 3 & .49 \\
\hline 55 & 1 & .16 & $222-227$ & 2 & .33 \\
\hline 54 & 3 & .49 & $216-221$ & 2 & .33 \\
\hline 53 & & & $210-215$ & 3 & .49 \\
\hline 52 & 3 & .49 & 204-209 & 2 & .33 \\
\hline 51 & 10 & 1.63 & $198-203$ & 1 & .16 \\
\hline 50 & 4 & .65 & $192-197$ & 5 & .82 \\
\hline 49 & 5 & .82 & $186-191$ & 1 & .16 \\
\hline 48 & 9 & 1.47 & $180-185$ & 4 & .65 \\
\hline 47 & 2 & .33 & $174-179$ & 2 & .33 \\
\hline 46 & 10 & 1.63 & $168-173$ & 1 & .16 \\
\hline 45 & 13 & 2.12 & $162-167$ & 3 & .49 \\
\hline 44 & 8 & 1.31 & $156-161$ & 4 & .65 \\
\hline 43 & 10 & 1.63 & $150-155$ & 21 & 3.43 \\
\hline 42 & 5 & .82 & $144-149$ & 40 & 6.52 \\
\hline 41 & 8 & 1.31 & $138-143$ & 74 & 12.07 \\
\hline 40 & 21 & 3.43 & $132-137$ & 41 & 6.69 \\
\hline 39 & 45 & 7.34 & $126-131$ & 29 & 4.73 \\
\hline 38 & 32 & 5.22 & $120-125$ & 39 & 6.36 \\
\hline 37 & 45 & 7.34 & $114-119$ & 115 & 18.76 \\
\hline 36 & 62 & 10.11 & $108-113$ & 46 & 7.50 \\
\hline 35 & 66 & 10.76 & $102-107$ & 47 & 7.66 \\
\hline 34 & 43 & 7.01 & $96-101$ & 25 & 4.08 \\
\hline 33 & 52 & 8.48 & $90-95$ & 17 & 2.77 \\
\hline 32 & 61 & 9.95 & $84-89$ & 12 & 1.96 \\
\hline 31 & 58 & 9.46 & $78-83$ & 9 & 1.47 \\
\hline 30 & 21 & 3.43 & $72-77$ & 15 & 2.45 \\
\hline 29 & 9 & 1.47 & $66-71$ & 19 & 3.10 \\
\hline 28 & 1 & .16 & $60-65$ & 5 & .82 \\
\hline 27 & 2 & .33 & $59 \&<$ & 9 & 1.47 \\
\hline Total & 613 & 100.00 & Total & 613 & 100.00 \\
\hline
\end{tabular}


for the 613 for whom birthdates were obtained was 36.5 years. Experience for the 613 ranged from 27 to 345 months and averaged 125.0 months (10.42 years). The distributions of age and experience appear in Table 1.

A total of 4,423 ATCS Performance Evaluation Forms were completed for the 614 subjects; 697 of the 4,423 were submitted by Supervisors, 885 by Crew Chiefs, and 2,841 by journeyman controllers. Prior to coding and processing, the forms were sorted to determine the number received by each controller from personnel of the three different levels. It was ascertained that each of 576 of the 614 was rated by one or more of the 78 Supervisors, 594 by one or more of the 117 Crew Chiefs, and 609 by one or more of the 614 journeymen. Some 455 of the ATCSs received only one supervisory evaluation, 121 received two, and 38 none. Twenty received no rating by a Crew Chief, 370 were rated by one, 157 by two, and 67 by three Crew Chiefs. Only five controllers failed to be evaluated by at least one peer, whereas 16 were rated by one, 39 by two, 120 by three, 146 by four, and 288 by five or more of their colleagues.

The initial step in processing each ATCS Performan Evaluation Form involved coding, or quantification, of the ratings. As pointed out zarlier, an evaluation of "inadequate" on an item of performance was coded as "1," "marginal" as '2," and so forth, with "outstanding" being asigned a code of "7." The midpoint on the deicriptive scale was "average (or good)," which :orresponded to a quantitative, or coded, rating if " $4 . "$

Dealing first with the forms submitted by supervisors, the coded ratings of each controller in the 20 aspects of Radar Control were tallied or each form, summed for both forms when ated by two Supervisors, and then divided by he number of element ratings comprising the um, to obtain an average referred to as the ubject's 'Mean Supervisory 'R' (Radar Control) rating." Similar techniques were used to deterine each controller's "Mean Supervisory ' $\mathrm{L}$ ' Local Control) Rating," "Mean Supervisory I' (General) Rating," and "Mean Supervisory ?' (Relative) Rating." The four values were ien averaged to obtain each subject's "Mean upervisory 'RLGR' Rating." The same proceures were employed to determine the mean $R$,
L, G, R, and RLGR Ratings of the controller by his Crew Chief(s) and also corresponding means of ratings by his coworkers, or peers. Lastly, five summary measures of performance were derived for each ATCS by averaging the means of ratings rendered by the Supervisors, Crew Chiefs, and Coworkers. They were designated as the "Overall Radar," "Overall Local," "Overall General," "Overall Relative Proficiency," and "Overall RLGR" ratings.

Reliability of RLGR Ratings. Inasmuch as the rating forms were unsigned, dual ratings received by each ATCS from personnel of each source level were arbitrarily designated as the "first" and "second" and other multiple ratings as the "third," "fourth," "fifth," and so forth. Identification of the source level was maintained so as to permit computation of the (Pearson product-moment) correlations between the sets of ratings. Although not shown in any table, the correlations between the RLGR ratings by coworkers ranged from .21 to .47 and, through use of z-coefficient transformation techniques, were found to average .39. The correlations between the first versus the second and third Crew Chief RLGR Ratings were .45 and .54, respectively, .40 between the second and third, and the average of the three was .46. The RLGR Ratings of the 121 ATCSs by two different Supervisors correlated .62. Although none of these coefficients should be regarded as exceptional, most of them are within the range of those generally reported in the open scientific literature for studies involving job performance ratings of personnel in various occupational specialties. ${ }^{5}$ 915

Empirical Interrelationships of Age, Experience, and RLGR Ratings. The intercorrelations of the Supervisory, Crew Chief, and Peer RLGR Ratings, the Overall RLGR Ratings, and the empirical relationships of the four criterion measures to both Chronological Age and Length of FAA ATC Experience are shown in Table 2. (All correlation coefficients, or " $r$ 's," appearing in the table are of the Pearson product-moment type; the same is true with respect to the r's presented in all subsequent sections of this report except where otherwise noted.) The Mean Supervisory RLGR Ratings correlated .58 with those of the Crew Chiefs and .59 with those of the journeymen ATCSs, whereas the latter correlated .56 with those based on Crew Chief evaluation. 
Table 2. Intercorrelations of RLGR ratings rendered by Supervisors, Crew Chiefs, and ATCS coworkers, and correlations of ratings with age and FAA ATC experience.

\begin{tabular}{|c|c|c|c|c|c|c|c|c|}
\hline & & & & $\begin{array}{l}\text { Crew } \\
\text { Chiefs }\end{array}$ & $\begin{array}{l}\text { Team } \\
\text { Peers }\end{array}$ & $\begin{array}{l}\text { Overal1 } \\
\text { Average } \\
\end{array}$ & $\begin{array}{c}\text { Chronol. } \\
\text { Age }\end{array}$ & $\begin{array}{c}\text { FAA ATC } \\
\text { Exper. }\end{array}$ \\
\hline & $\underset{\mathrm{N}}{\mathrm{Max}}$ & Mean & S.D. & $\mathbf{N}$ & $\mathbf{r}$ & $\mathbf{N}$ & $\mathbf{N}$ & $\mathbf{N}$ \\
\hline $\begin{array}{l}\text { Composite RLGR } \\
\text { by Supervișors }\end{array}$ & 576 & 5.13 & .88 & $\begin{array}{r}558 \\
.58\end{array}$ & $\begin{array}{ll}571 & \\
& .59\end{array}$ & $\begin{array}{r}576 \\
.86\end{array}$ & $\begin{array}{l}576 \\
-.36\end{array}$ & $\begin{array}{l}576 \\
-.23\end{array}$ \\
\hline $\begin{array}{l}\text { Composite RLGR } \\
\text { by Crew Chiefs }\end{array}$ & 594 & 5.29 & .85 & & $\begin{array}{l}589 \\
.56\end{array}$ & $\begin{array}{r}594 \\
.85\end{array}$ & $\stackrel{593}{-.34}$ & $\begin{array}{l}593 \\
-.23\end{array}$ \\
\hline $\begin{array}{l}\text { Composite RLGR } \\
\text { by Team Coworkers }\end{array}$ & 609 & 4.99 & .71 & & & $\begin{array}{ll}609 & \\
& .83\end{array}$ & $\begin{array}{l}608 \\
-.42\end{array}$ & $\begin{array}{l}608 \\
-.29\end{array}$ \\
\hline $\begin{array}{l}\text { Overall RLGR, Avg. of } \\
\text { Supv., Chfs., Peers }\end{array}$ & 614 & 5.14 & .68 & & & & $\frac{613}{-.44}$ & $\frac{613}{-.29}$ \\
\hline $\begin{array}{l}\text { Chronological } \\
\text { Age }\end{array}$ & 613 & 36.50 & 5.49 & & & & & .613 .63 \\
\hline $\begin{array}{l}\text { Months of FAA ATC } \\
\text { Experience }\end{array}$ & 613 & 124.97 & 38.30 & & & & & \\
\hline
\end{tabular}

*All correlation coefficients are statistically significant at the .01 level. 
The Overall Average RLGR Rating correlated $.86, .85$, and .83 with the Mean RLGR Ratings of the Supervisors, Crew Chiefs, and Coworkers, respectively. Low but statistically significant $(p<.01)$ and negative r's, ranging from --.23 to -.29 , were obtained between Experience and the four criterion variables. Although a positive correlation of .63 was found between Age and Experience, the inverse relationship of Age to each of the four performance measures was significantly $(p<.05)$ greater than obtained for Experience. Age correlated - .36 with the Mean Supervisory RLGR Rating, -.34 with the corresponding composite Crew Chief rating, -.42 with the Mean Coworker RLGR Rating, and -.44 with the Overall Average RLGR Rating. While these coefficients are of substantial magnitudes and all statistically significant $(p<.01)$, they should be regarded as grossly attenuatedas should those pertaining to length of experience. Almost 88 per cent of the ATCSs were between the ages of 27 and 44 and about 92 per cent also had less than 156 months (i.e., under 13 years) of experience in FAA ATC work. Such restriction-of-range effects indicated the need for other analyses whereby the means of the performance ratings could be ascertained and compared for the ATCSs of various age and experience groupings.

Means of RLGR Ratings by ATCS Age Group. After reviewing the age distribution (Table 1), the investigators divided the sample into six subgroups for a series of analyses aimed at determining the extent to which the performance rating means might vary in accordance with chronological age. The first of the six consisted of the 33 subjects of age 30 and younger; the next four were the five-year age intervals, "31-35," " $36-40, "$ " $41-45$," and " $46-50$," which contained $280,205,44$, and 30 cases, respectively; the sixth category, "51 and older," contained the remaining 21 cases. Averages of the Mean RLGR Supervisory Ratings for the subjects in the various age brackets were computed and plotted. The same procedure was employed with respect so the Mean Crew Chief RLGR Ratings, the Mean Coworker RLGR Ratings, and the Orerall RLGR Ratings. The results are presented in Figure 1.

In examining Figure 1, it should be noted that the plotted means of the four criterion measures all follow a similar pattern; they indicate that the ATCSs of age 30 and younger generally received slightly higher ratings than those of age $31-35$ or $36-40$, and that the controllers within each succeeding age bracket tended to receive progressively lower mean ratings. A one-way analysis of variance (ANOVA) of the Overall RLGR Ratings and ANOVA's of RLGR ratings rendered by control personnel of each of the three different levels all yielded significant Fratios, indicating the presence of statistically significant differences between the means of ratings (of each type) for two or more of the age subgroups. It was subsequently determined, through use of Scheffe's "S-Method" that the means of each of the four criterion measures for ATCSs of age 30 and less, 31-35, and even those of age $36-40$, were significantly higher than those obtained for controllers of age $46-50$ or 51 and older. Moreover, the ATCSs of age 41-45 received significantly lower mean ratings from both their Crew Chiefs and Coworkers than did ATCSs of either of the two youngest subgroups and their mean Overall RLGR Rating also differed significantly from those of both younger subgroups.

A finding of incidental interest was that the means of the ratings rendered by the ATCSs were consistently lower, but generally not significantly lower, than those of the Crew Chiefs for controllers of every age bracket, and also lower than those of the Supervisors for all except the two oldest subgroups of controllers. Means of the Crew Chiefs ratings were higher than those of the Supervisors for five of the six subgroups, with the greatest differences, which were not statistically significant, pertaining to the ATCSs of age 46-50 and 51 and older. (Except where otherwise noted, all mean differences discussed in this and succeeding sections of the report were tested for statistical significance by Scheffe's method.)

The question as to whether the ages of the raters may have influenced their ratings of differentially aged ATCSs prompted three analyses: one each on the ratings rendered by Supervisors, by Crew Chiefs, and Coworkers. (The results are presented in Appendices 2, 3, and 4.) Each such analysis was, by necessity, restricted to the data of only those raters who declined the anonymity privilege (i.e., those who signed their evaluation forms). In the first analysis, 381 completed rating forms for a total of 280 ATCSs 


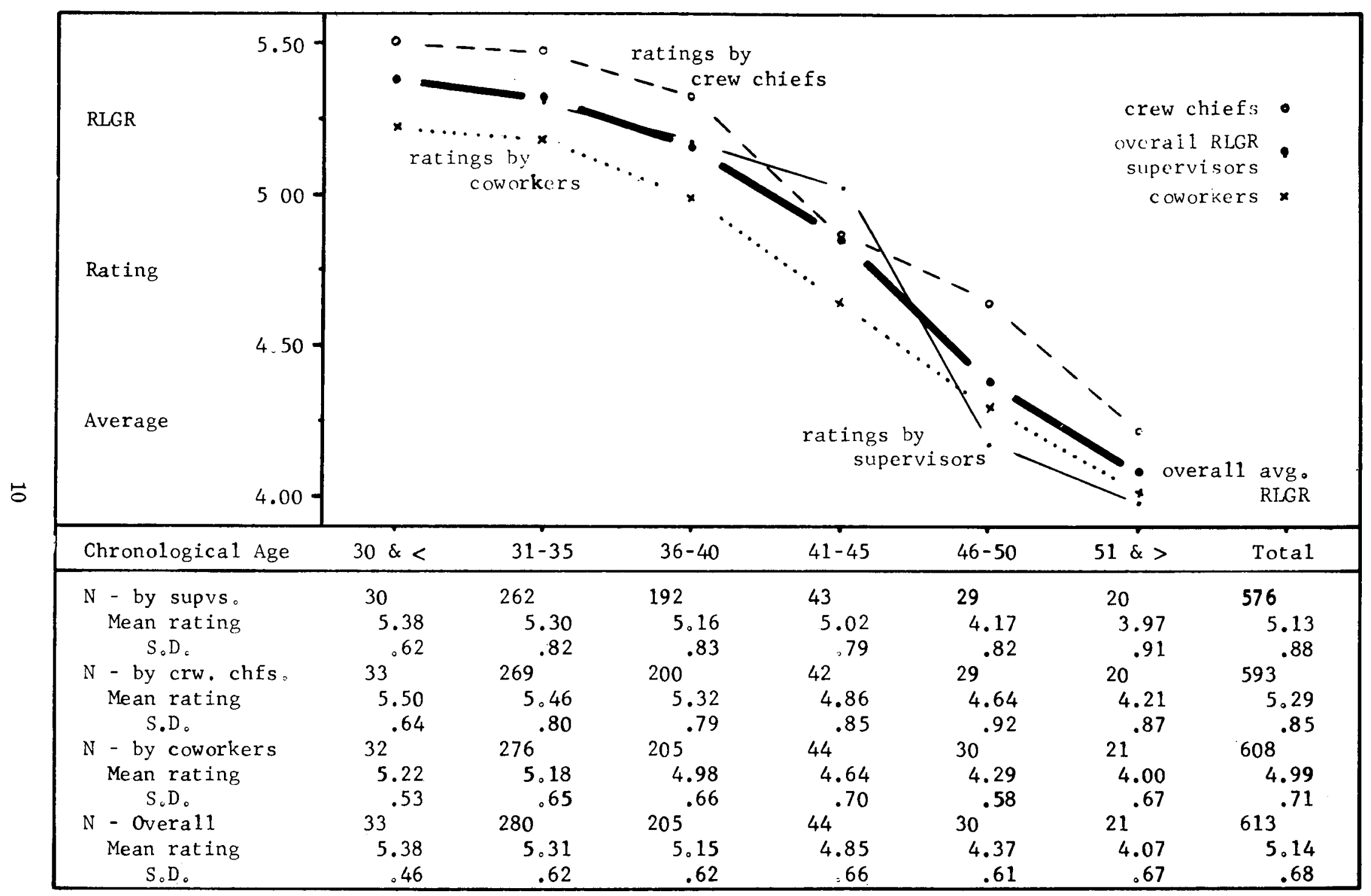

Figure 1. Means of RLGR job performance ratings by age level for Terminal ATCSs evaluated by supervisors, crew chiefs, and journeymen coworkers. A total of 121 ATCSs were rated by two supervisors rather than one; 224 were rated by two crew chiefs and 67 by three crew chiefs; 593 were rated by at least two coworkers, and 288 of the 593 were rated by five or more colleagues. 
were identified as originating with 41 Supervisors. Ninety of the 381 were from 10 Supervisors of age 45 and younger, 154 originated with 17 who were $46-50$, and 137 were from 14 of age 51 or older (Appendix 2). No significant or appreciable differences were found between the means of the ratings rendered by Supervisors of the respective age categories for ATCSs within any of the age groupings, "35 or younger," "36-40," "41-45," and " 46 or older." In contrast, a corresponding analysis of 545 Crew Chief RLGR Ratings revealed that the raters of age 40 and younger tended to rate the ATCSs of age $41-45$ and 46 and older somewhat lower than did the Crew Chiefs of age $41-45$ and appreciably lower than the raters of age 46 and older (Appendix 3), but the mean differences were not statistically significant. Moreover, an analysis of 654 Coworker RLGR Ratings yielded results (Appendix 4) which, like those of the Supervisors, demonstrated no general relationship between the ages of the raters and their evaluations of the relatively young or clder groups of ATCSs.

Means of RLGR Ratings by FAA ATC Experience Groupings. In order to assess the relationship between Length of FAA ATC Experience and ATCS performance, the sample was divided into eight subgroups, with each subgroup having ATC service within a specified range. The first category, designated "less than five years," included only nine cases. Fortyeight subjects who had FAA ATC work of at least 60 months but less than 84 months (seven years) were categorized as having " $5-6$ " years. The next three categories, " $7-8$," "9-10," and "11-12," contained 101, 229, and 176 cases, respectively. Inasmuch as only 50 subjects possessed experience of 156 months (13 years) or more, 21 were grouped in terms of the four-year interval " $13-16, " 16$ were designated as having "17-20," and 13 as having "21 or more." Averages of the Mean Supervisory RLGR Ratings were then computed and plotted and the procedures were replicated with respect to the Mean Crew Chief RLGR Ratings, the Mean Coworker RLGR Ratings, and the Overall RLGR Ratings. The results are shown in Figure 2.

Figure 2, as did Figure 1, reflects a high degree of congruency between the patterns of the plotted means of the four criterion measures. (Although the Crew Chiefs tended to rate the controllers of most experience subgroups somewhat higher than either the Supervisors or the Coworkers, the only differences which proved statistically significant were between the means of the Crew Chief and Coworker ratings of those ATCSs having 9-10 or 11-12 years experience.) The figure illustrates that the Supervisors, as well as the Crew Chiefs and journeymen, generally rated the controllers having $5-6,7-8$, or 11-12 years of service slightly higher than those having less than five years of experience and appreciably higher than those having 13-16, 17-20, or 21 or more years. Although these findings did not stem from a longitudinal study and, as will be discussed later, are also confounded to some extent by age effects, they nevertheless suggest that significant decrements in performance are apt to occur at about the 13th year of many of the TATC controllers' careers.

An analysis of variance of the Overall RLGR Ratings yielded a significant $\mathrm{F}$-ratio and it was subsequently ascertained, by Scheffe's technique, that the mean performance level of each of the three most experienced subgroups differed significantly $(p<.05$ or better $)$ from the means established for ATCSs who had 5-6, 7-8, 9-10, or 11-12 years of service, whereas none of the mean differences which involved the least experienced subgroup (i.e., less than five years) proved statistically significant.

Significant F-ratios were also obtained in ANOVA's of the ratings rendered by control personnel of each level. The Supervisors rated the ATCSs who had over 20 years of service significantly lower $(p<.05)$ than all other subgroups. Other significant mean differences with respect to the Supervisory evaluations pertained to the subjects with 17-20 years experience versus those having 5-6, 9-10, or 11-12 years, and controllers with $13-16$ years experience versus those with $5-6$ or $9-10$ years. Moreover, the probability of chance occurrence of differences such as between the means of the Supervisory ratings of ATCSs having 17-20 years experience and those having either 7-8 or 11-12 years was found to be less than 10 in 100 (i.e., $p<.10$ ). The Crew Chiefs tended to rate the controllers of the two most experienced subgroups significantly lower than those having 5-6, 7-8, 9-10, or 11-12 years service. The same was true with respect to the ratings rendered by Coworkers; however, the latter also tended to rate the controllers of 


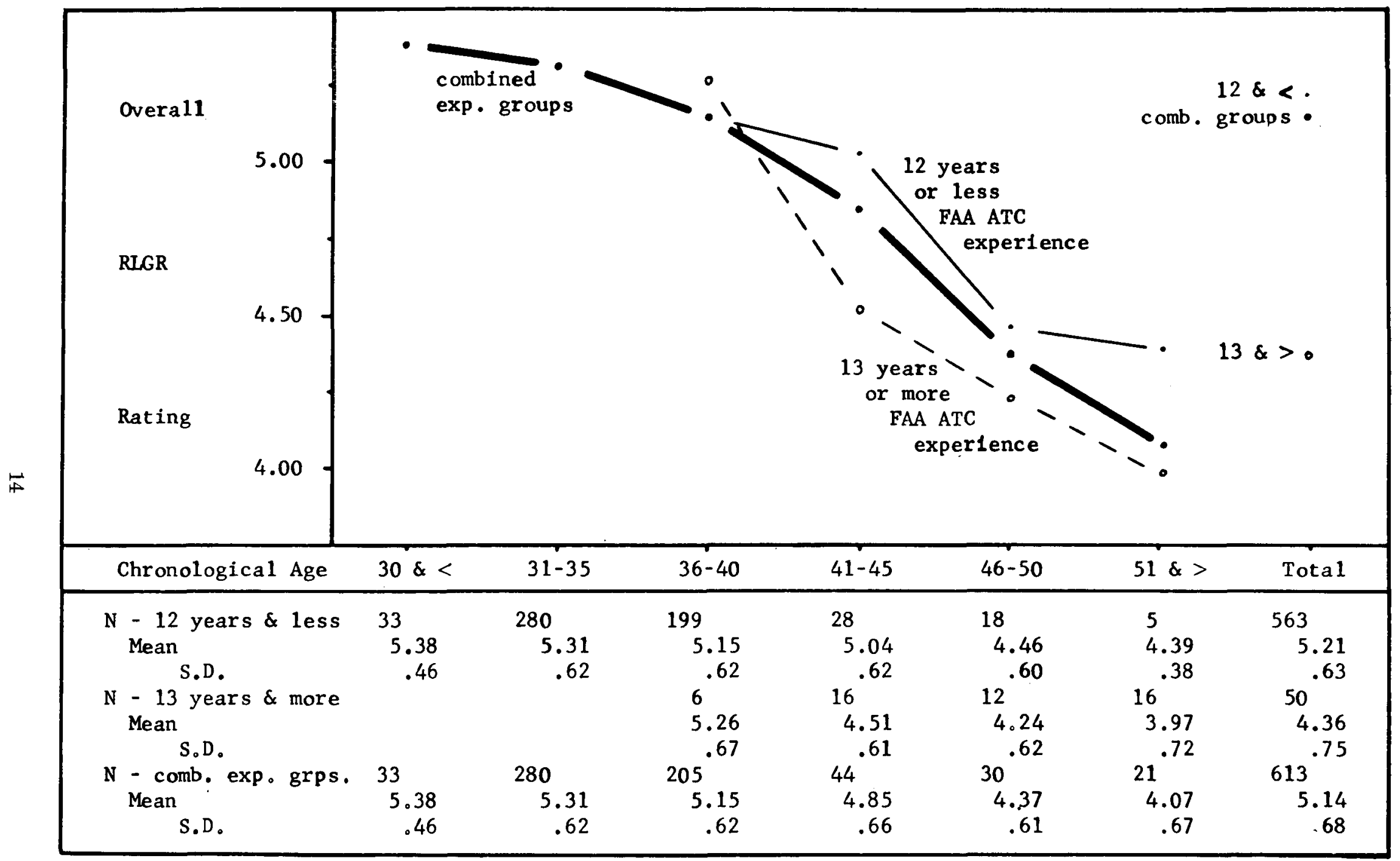

FIGURE 3. Means of Overall RLGR Ratings by age level for Terminal ATCSs of dichotomized FAA ATC experience groups " 12 years or less" and "13 years or more." Disregarding experience, differences between the mean ratings of each of the following groups are significant $(p<.05):$ ATCSs of either age 30 and younger or 31-35 versus those either 41-45, 46-50, or 51 and older; those of age 36-40 versus those either 46-50 or 51 and older; and those of age 41-45 versus the oldest group. Of the differences between experience subgroups within age levels, only that for ATCSs of age 41-45 is significant. 
the correlational analyses. Although not dealt with in earlier phases of the study, age at entry into FAA ATC training was also scheduled for inclusion.

The intercorrelations of Training Entry Age, Age When Rated, Years of FAA ATC Experience, and performance (as represented by the composite RLGR measure) are shown in Table 3 for the journeymen of the separate and combined facilities. The facilities are listed in order of IFR operations performed during 1969.

Correlative Data for Combined Facitities. Looking first at the results shown in the lower section of Table 3 for all 613 subjects, it should be noted that the correlation between Training Entry Age and Age When Rated was .81. This highly significant $(p<.01)$ relationship suggested that many of the controllers who were relatively old at the time the surrey was conducted may have begun their career in the air traffic management system at a more advanced age than the younger journeymen. This was verified by a bivariate frequency distribution which indicated that 32 (33.7 per cent) of the 95 journeymen who were over 40 years of age at the time the rating data were collected had been 36 or older upon entry into FAA ATC training, that 27 (28.4 per cent) entered when 31 to 35 years old, and that only 36 (37.9 per cent) began their career before age 31 . As noted earlier, several CAMI follow-up studies $^{12410121314}$ of Academy entrants have shown that personnel older than 30, and particularly those over 35, generally tend to experience much greater difficulty than their younger colleagues in passing the Academy's basic training course and in successfully completing subsequent phases of training. Inasmuch as almost 72 per cent of the 95 oldest journeymen involved in the present study were known to hare been orer 30 years old when appointed to training, there is the possibility that relatively few of them were erer among the top performers at any stage of their careers. While the degree to which this may have actually occurred cannot be ascertained from the data and information collected, some likelihood of such uncontrollable bias in the selection of the sample must be noted. In other words, significant proportions of the differences between the mean levels of job performance of the older and younger subgroups may not have been due to aging effects after entry into the FAA but rather to pre-entry aging effects (such as deficits in learning ability, aptitudes, motivational factors, and the like) which might have precluded the older ATCSs from performing on a highly competitive basis with their younger counterparts throughout all career phases.

The correlation between Entry Age and Age When Rated was, as mentioned, .81. Had a perfect positive correlation (i.e., an $\mathbf{r}$ of 1.00) been obtained between the two, then Years of FAA ATC Experience would have been invariable, or identical, for all subjects and thus would have precluded any relationship whatsoever between experience and performance or between experience and either age variablebecause FAA ATC Experience was, for all subjects except those having breaks in service, simply the difference between their ages at entry and when rated.

However, the total sample yielded correlations of .63 between Age When Rated and experience and .03 between the latter and Entry Age. Moreover, significant inverse relationships were obtained between the criterion variable (Overall RLGR Rating) and both age variables and also length of experience, with the lowest of the three r's, a -.29 , pertaining to experience. Training Entry Age correlated - .35 with performance, whereas Age When Rated, which had correlated .63 with experience, yielded a validity coefficient of -.44. Inasmuch as length of experience was generally the difference between Entry Age and Age When Rated, logic would dictate that the coefficient of -.29 also reflects the relationship that would have been obtained between performance and Age When Rated if all subjects had been of the same Entry Age.

Comparison of Empirical Relationships by Facility. Returning to Table 3 for a comparison of the intercorrelations by facility, it should be noted that the r's between the two age variables ranged from .64 (for the Denver, or "DEN," subgroup) to .97 (for the ATCSs at the Norfolk, or "ORF," Tower). As expected, most correlations between Experience and Entry Age were rather small and only one, a -.38 (pertaining to the Kansas City facility, designated as MKC") proved statistically significant $(p<.05)$. In contrast, the coefficients reflecting the relationship of Experience to Age When Rated ranged from 
Table 3. Intercorrelations of job performance, age, and experience variables for ATCSs of each of 17 TATC facilities.

\begin{tabular}{|c|c|c|c|c|c|c|c|c|c|c|c|c|c|c|c|}
\hline $\begin{array}{l}\text { Fac1 } 1 . \\
\text { and } N \\
\text { ATCSs }\end{array}$ & 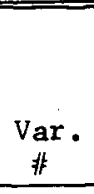 & Mean & S.D. & $\begin{array}{l}\text { Variab } \\
1 \\
\text { Trng。 } \\
\text { Entry } \\
\text { Age } \\
\end{array}$ & $\begin{array}{l}\text { les \& I } \\
\text { Age } \\
\text { When } \\
\text { Rated }\end{array}$ & $\begin{array}{l}\quad 3 \\
\text { ntercorre } \\
\text { Years } \\
\text { FAA ATC } \\
\text { Exper } 1 .\end{array}$ & $\begin{array}{l}\text { lations } \\
\quad 4 \\
\text { Overal1 } \\
\text { RLGR } \\
\text { Rating }\end{array}$ & $\begin{array}{l}\text { Fac11, } \\
\text { and N , } \\
\text { ATCSs }\end{array}$ & $\begin{array}{c}\text { Var. } \\
\#\end{array}$ & Mean & S.D. & $\begin{array}{l}\text { Varial } \\
1 \\
\text { Trng. } \\
\text { Entry } \\
\text { Age } \\
\end{array}$ & $\begin{array}{l}\text { les \& In } \\
\quad 2 \\
\text { Age } \\
\text { When } \\
\text { Rated } \\
\end{array}$ & $\begin{array}{l}\text { ntercorre } \\
3 \\
\text { Years } \\
\text { FAA ATC } \\
\text { Exper } 1 .\end{array}$ & 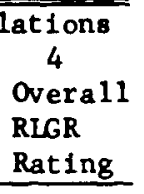 \\
\hline $\begin{array}{r}\text { ATL } \\
49\end{array}$ & $\begin{array}{l}1 \\
2 \\
3 \\
4 \\
\end{array}$ & $\begin{array}{r}25.6 \\
35.9 \\
10.4 \\
5.2 \\
\end{array}$ & $\begin{array}{l}4.1 \\
5.2 \\
3.6 \\
0.5 \\
\end{array}$ & & $.72^{\star \star}$ & $\begin{array}{l}-.06 \\
.65^{\star *}\end{array}$ & $\begin{array}{l}-.16 \\
-.39^{* *} \\
=.39^{* *}\end{array}$ & $\begin{array}{r}\text { CLE } \\
32\end{array}$ & $\begin{array}{l}1 \\
2 \\
3 \\
4 \\
\end{array}$ & $\begin{array}{r}25.1 \\
35.9 \\
10.9 \\
5.2 \\
\end{array}$ & $\begin{array}{l}3.1 \\
4.7 \\
2.9 \\
0.8 \\
\end{array}$ & & $.80^{\star \star}$ & $\begin{array}{l}.24 \\
.77^{* *}\end{array}$ & $\begin{array}{l}-.32 \\
-.42^{\star} \\
-.35^{\star}\end{array}$ \\
\hline $\begin{array}{r}\text { MIA } \\
58\end{array}$ & $\begin{array}{l}1 \\
2 \\
3 \\
4\end{array}$ & $\begin{array}{r}25.6 \\
36.4 \\
10.9 \\
5.1 \\
\end{array}$ & $\begin{array}{l}4.0 \\
5.9 \\
3.8 \\
0.6 \\
\end{array}$ & & $.77^{\star \star x}$ & $\begin{array}{l}.13 \\
.73^{* *}\end{array}$ & $\begin{array}{l}-.28^{*} \\
-.38^{* *} \\
-.29^{*}\end{array}$ & $\begin{array}{r}\text { MSP } \\
28\end{array}$ & $\begin{array}{l}1 \\
2 \\
3 \\
4 \\
\end{array}$ & $\begin{array}{r}26.4 \\
37.2 \\
10.9 \\
5.2 \\
\end{array}$ & $\begin{array}{l}2.8 \\
4.5 \\
2.9 \\
0.6 \\
\end{array}$ & & $.75^{\star \star}$ & $\begin{array}{l}.15 \\
.76^{\star *}\end{array}$ & $\begin{array}{l}-.21 \\
-.46^{*} \\
-.48^{* *}\end{array}$ \\
\hline $\begin{array}{r}\mathrm{DCA} \\
51\end{array}$ & $\begin{array}{l}1 \\
2 \\
3 \\
4 \\
\end{array}$ & $\begin{array}{r}25.7 \\
35.1 \\
9.4 \\
5.2 \\
\end{array}$ & $\begin{array}{l}3.3 \\
3.9 \\
2.2 \\
0.8 \\
\end{array}$ & & $.80^{\star \star}$ & $\begin{array}{l}-.09 \\
.52^{\star \star}\end{array}$ & $\begin{array}{r}-.12 \\
.00 \\
.17\end{array}$ & $\begin{array}{r}\mathrm{MKC} \\
33\end{array}$ & $\begin{array}{l}1 \\
2 \\
3 \\
4 \\
\end{array}$ & $\begin{array}{r}26.8 \\
37.2 \\
10.4 \\
5.3 \\
\end{array}$ & $\begin{array}{l}5.5 \\
7.3 \\
2.9 \\
0.6 \\
\end{array}$ & & $.93^{\star \star}$ & $\begin{array}{l}.38^{\star} \\
.70^{\star \star}\end{array}$ & $\begin{array}{l}-.54^{\star \star} \\
-.55^{\star \star} \\
-.37^{\star}\end{array}$ \\
\hline $\begin{array}{r}\text { DTW } \\
40\end{array}$ & $\begin{array}{l}1 \\
2 \\
3 \\
4\end{array}$ & $\begin{array}{r}25.2 \\
35.9 \\
10.7 \\
5.2\end{array}$ & $\begin{array}{l}2.9 \\
3.8 \\
2.4 \\
0.6\end{array}$ & & $.78^{\star \star}$ & $\begin{array}{l}.07 \\
.6 T^{\star *}\end{array}$ & $\begin{array}{l}-.31^{\star} \\
-.37^{*} \\
-.24\end{array}$ & $\begin{array}{r}\text { TPA } \\
32\end{array}$ & $\begin{array}{l}1 \\
2 \\
3 \\
4\end{array}$ & $\begin{array}{r}27.6 \\
37.2 \\
9.5 \\
4.9\end{array}$ & $\begin{array}{l}4.8 \\
5.8 \\
4.6 \\
0.5\end{array}$ & & $.65^{\star \star}$ & $\begin{array}{r}-.24 \\
.58 * \star\end{array}$ & $\begin{array}{l}-.28 \\
-.37^{*} \\
-.20\end{array}$ \\
\hline $\begin{array}{r}\text { SAT } \\
29\end{array}$ & $\begin{array}{l}1 \\
2 \\
3 \\
4\end{array}$ & $\begin{array}{r}25.6 \\
36.0 \\
10.6 \\
5.0\end{array}$ & $\begin{array}{l}3.4 \\
4.6 \\
2.7 \\
0.7\end{array}$ & & $.79^{\star \star}$ & $\begin{array}{l}.09 \\
.67^{* *}\end{array}$ & $\begin{array}{l}-.37^{\star} \\
-.52^{\star *} \\
-.40^{*}\end{array}$ & $\begin{array}{r}\text { CMH } \\
31\end{array}$ & $\begin{array}{l}1 \\
2 \\
3 \\
4\end{array}$ & $\begin{array}{r}27.6 \\
37.7 \\
10.1 \\
5.3\end{array}$ & $\begin{array}{l}5.4 \\
6.8 \\
3.4 \\
0.8\end{array}$ & & $.87^{\star \star}$ & $\begin{array}{l}.18 \\
.64^{* *}\end{array}$ & $\begin{array}{l}-.53^{k \star} \\
-.66^{* \star} \\
-.52^{* \star}\end{array}$ \\
\hline $\begin{array}{r}\text { BOS } \\
42\end{array}$ & $\begin{array}{l}1 \\
2 \\
3 \\
4\end{array}$ & $\begin{array}{r}26.0 \\
36.6 \\
10.6 \\
5.2 \\
\end{array}$ & $\begin{array}{l}4.0 \\
5.1 \\
2.9 \\
0.7\end{array}$ & & $.83^{x \times}$ & $\begin{array}{l}.08 \\
.61^{* *}\end{array}$ & $\begin{array}{l}-.59^{\star x} \\
-.55^{\star *} \\
-.14\end{array}$ & $\begin{array}{r}\text { ORF } \\
35\end{array}$ & $\begin{array}{l}1 \\
2 \\
3 \\
4\end{array}$ & $\begin{array}{r}29.1 \\
39.5 \\
10.4 \\
5.0\end{array}$ & $\begin{array}{l}6.6 \\
7.3 \\
1.7 \\
0.8 \\
\end{array}$ & & $.97^{\star \star}$ & $\begin{array}{l}.25 \\
.47^{\star \star}\end{array}$ & $\begin{array}{l}-.59^{\star x} \\
-.62^{\star *} \\
-.39^{\star}\end{array}$ \\
\hline $\begin{array}{r}\text { PHL } \\
38\end{array}$ & $\begin{array}{l}1 \\
2 \\
3 \\
4\end{array}$ & $\begin{array}{r}26.9 \\
38.2 \\
11.2 \\
4.8 \\
\end{array}$ & $\begin{array}{l}5.5 \\
7.2 \\
4.3 \\
0.8\end{array}$ & & $.81^{\star \star}$ & $\begin{array}{l}.14 \\
.69^{* * x}\end{array}$ & $\begin{array}{l}-.40^{*} \\
-.51^{* *} \\
-.38^{*}\end{array}$ & $\begin{array}{r}\text { MEM } \\
28\end{array}$ & $\begin{array}{l}1 \\
2 \\
3 \\
4\end{array}$ & $\begin{array}{r}25.2 \\
35.3 \\
10.0 \\
5.5 \\
\end{array}$ & $\begin{array}{l}2.8 \\
5.0 \\
3.8 \\
0.6 \\
\end{array}$ & & .65 & $\begin{array}{l}.11 \\
.82^{\star \star}\end{array}$ & $\begin{array}{l}-.48^{*} \\
-.60^{*} \\
-.45^{*}\end{array}$ \\
\hline $\begin{array}{r}\text { STL } \\
31\end{array}$ & $\begin{array}{l}1 \\
2 \\
3 \\
4\end{array}$ & $\begin{array}{r}25.5 \\
35.0 \\
9.5 \\
5.2 \\
\end{array}$ & $\begin{array}{l}3.1 \\
3.7 \\
2.1 \\
0.6 \\
\end{array}$ & & $.82^{\star \star}$ & $\begin{array}{l}-.05 \\
.52^{\star *}\end{array}$ & $\begin{array}{l}-.32 \\
-.40^{*} \\
-.26\end{array}$ & $\begin{array}{r}\text { IND } \\
22\end{array}$ & $\begin{array}{l}1 \\
2 \\
3 \\
4 \\
\end{array}$ & $\begin{array}{r}26.3 \\
36.9 \\
10.6 \\
5.2 \\
\end{array}$ & $\begin{array}{l}4.2 \\
5.1 \\
2.8 \\
0.7\end{array}$ & & $.84^{\star \star}$ & $\begin{array}{c}-.08 \\
.54 * \star\end{array}$ & $\begin{array}{l}-.14 \\
-.39 \\
-.42^{*}\end{array}$ \\
\hline $\begin{array}{r}\mathrm{DEN} \\
34\end{array}$ & $\begin{array}{l}1 \\
2 \\
3 \\
4\end{array}$ & $\begin{array}{r}24.07 \\
35.4 \\
10.8 \\
5.0\end{array}$ & $\begin{array}{l}3.2 \\
4.4 \\
3.3 \\
0.7\end{array}$ & & $.64^{* *}$ & $\begin{array}{l}-.09 \\
.70^{* *}\end{array}$ & $\begin{array}{l}-.22 \\
-.37^{*} \\
-.28\end{array}$ & $\begin{array}{l}\text { TOTAL } \\
613\end{array}$ & $\begin{array}{l}1 \\
2 \\
3 \\
4\end{array}$ & $\begin{array}{r}26.1 \\
36.5 \\
10.4 \\
5.1\end{array}$ & $\begin{array}{l}4.3 \\
5.5 \\
3.2 \\
0.7\end{array}$ & & $.81^{* *}$ & $\begin{array}{l}.03 \\
.63^{* *}\end{array}$ & $\begin{array}{l}-.35^{\star *} \\
-.44^{\star *} \\
-.29^{\star *}\end{array}$ \\
\hline
\end{tabular}

* Statistically significant at the .05 level; $* *$ Statistically significant at the .01 level. 
.47 to .82, all of which were significant at the .01 level of probability.

Entry Age was inversely related to the job ratings of personnel at every facility. These correlations ranged from -.12, for Washington National ("DCA") Airport, to -.59, for the Boston ("BOS") facility, five of the $17 \mathrm{r}$ "s were significant at the .01 level and four at the .05 level. The DCA Tower was also unusual in that it was the only facility for which the ATCS ratings failed to be inversely related to both Experience and Age When Rated. The correlation between the latter and the criterion variable for the remaining 16 facilities ranged from -.37 to -.66 , nine of which were significant at the .01 level and six at the .05 level. Aside from DCA, there was only one facility (Boston) at which Age When Rated failed to be more inversely related to performance than Entry Age. The lowest of the negative correlations between Experience and the criterion variable was -.14 (for Boston) and the highest was -.52 (for the "CMH," or Columbus, Ohio, facility). Five of the latter were significant at the .01 level and six at the .05 level. For most facilities, however, it was found that Experience was not as highly related to performance as was Age When Rated; moreover, at nine facilities, Experience also proved less effective than Entry Age as a predictor of performance.

Since several of the largest (negative) correlations between. performance and the two age variables and also between the criterion variable and Experience pertained to facilities which were among those which ranked rather low with respect to IFR traffic volume, each of the three sets of correlation coefficients were rank ordered and the ranks were then correlated against the IFR-traffic-volume ranks of the respective facilities. Although not shown in any table, the resulting "rho" coefficients ${ }^{6}$ were -.27 for Entry Age, -.47 for Age When Rated, and -.49 for Experience. Only the correlation of -.49 was statistically significant $(p<.05)$. Nevertheless, the latter two coefficients indicated that the inverse relationships between performance and both Age When Rated and Experience were inleed generally more pronounced at the facilities aving relatively low IFR traffic loads.

Comparison of Results for High-, Intermedizte-, and Low-Ranked IFR Facitities. Table 4 and Figures 5 and 6 present the results of analyses in which the total sample was divided into three subsamples. The subgroups were established by categorizing the facilities in terms of IFR operations performed during the fiscal year (FY) 1969. The first subsample, designated as "High IFR," consisted of 198 subjects who worked at the four facilities which had over 300,000 IFR operations each. The "Intermediate IFR Subsample" consisted of 206 who were stationed at any of the six facilities having over 200,000 but less than 300,000 such operations, and the remaining 209, referred to as the "Low IFR Subsample," represented all journeymen of the seren facilities which handled lesser amounts of IFR traffic. (It should be emphasized that the three categories were established for research purposes only; the official classification of each of the 17 facilities was "Level-III," the highest of three levels into which any TATC facility was classified at the time the study was conducted.)

Table 4 shows the intercorrelations of the two age variables, FAA ATC Experience, and the criterion variable for the three subsamples. Correlations between the two age variables ranged from .75 to .85 , with the lowest being obtained for the High IFR Subsample and the highest relating to the subjects of the seven lowestranked facilities. As expected, Experience was not appreciably related to Entry Age for any subsample, whereas its correlation with Age When Rated was .59 for the Low IFR Subsample and .67 for the other two. There was no subsample for which performance failed to correlate more highly with Age When Rated than with Entry Age or Experience. A fact of even greater importance was that the highest of the validities for each of the three variables pertained to the Low IFR Subjects and that the lowest pertained to those of the four highestranked facitities. The validity coefficients of Entry Age for the High, Intermediate, and Low Subsamples, respectively, were $-.20,-.39$, and -.46; corresponding correlations for Age When Rated were $-.27,-.48$, and -.55 , and those involving Experience were -.19, -.31, and -.34. The Intermediate and the Low IFR Subsample differed significantly $(p<.05)$ from the High IFR Subsample with respect to the correlations between performance and each age variable. Other differences were not statistically signifi- 
Table 4. Intercorrelations of performance, age, and experience for three ATCS subsamples: those of TATC facilities having annual IFR operations of over $300,000 \mathrm{each}$, those with 200,000 to 300,000 , and those with less than 200,000 each.

\begin{tabular}{|c|c|c|c|c|c|c|c|}
\hline Groups of TATC Facilities \& N ATCSs & $\underset{\text { 非 }}{\operatorname{Var}}$ & Mean & S.D. & $\begin{array}{l}\text { Variab } \\
\quad 1 \\
\text { Trng. } \\
\text { Entry } \\
\text { Age }\end{array}$ & $\begin{array}{l}\text { les \& } 1 \\
\quad 2 \\
\text { Age } \\
\text { When } \\
\text { Rated }\end{array}$ & $\begin{array}{l}\text { Intercorre } \\
3 \\
\text { Yrs. of } \\
\text { FAA ATC } \\
\text { Experi. }\end{array}$ & $\begin{array}{l}\text { lations } \\
\quad 4 \\
\text { Overa } 11 \\
\text { RLGR } \\
\text { Rating }\end{array}$ \\
\hline $\begin{array}{l}\text { Four facilities having over } 300,000 \\
\text { Instrument Operations each during } \\
\text { 1968. (ATL, MIA, DCA \& DTW) } \\
\text { Grouped data for } 198 \text { ATCSs. }\end{array}$ & $\begin{array}{l}1 \\
2 \\
3 \\
4\end{array}$ & $\begin{array}{r}25.5 \\
35.8 \\
10.3 \\
5.2\end{array}$ & $\begin{array}{l}3.6 \\
4.9 \\
3.2 \\
0.6\end{array}$ & & .75 & $\begin{array}{r}-.09 \\
.67\end{array}$ & $\begin{array}{l}-.20 \\
-.27 \\
-.19\end{array}$ \\
\hline $\begin{array}{l}\text { Six facilities having } 200,000 \text { to } \\
300,000 \text { Instrument Operations each } \\
\text { during } 1968 \text {. (SAT, BOS, PHL, STL, } \\
\text { DEN \& CLE) Data for } 206 \text { ATCSs. }\end{array}$ & $\begin{array}{l}1 \\
2 \\
3 \\
4\end{array}$ & $\begin{array}{r}25.7 \\
36.3 \\
10.6 \\
5.1\end{array}$ & $\begin{array}{l}3.9 \\
5.2 \\
3.2 \\
0.7\end{array}$ & & .80 & $\begin{array}{r}.09 \\
.67\end{array}$ & $\begin{array}{l}-.39 \\
-.48 \\
-.31\end{array}$ \\
\hline $\begin{array}{l}\text { Seven facilities having less than } \\
200,000 \text { but over } 100,000 \text { Instru- } \\
\text { ment Operations each during } 1968 \text {. } \\
\text { (MSP, MKC, TPA, CMH, ORF, MEM \& } \\
\text { IND) Grouped data for } 209 \text { ATCSs. }\end{array}$ & $\begin{array}{l}1 \\
2 \\
3 \\
4\end{array}$ & $\begin{array}{r}27.1 \\
37.4 \\
10.3 \\
5.2\end{array}$ & $\begin{array}{l}5.0 \\
6.2 \\
3.2 \\
0.7\end{array}$ & & .85 & $\begin{array}{l}.08 \\
.59\end{array}$ & $\begin{array}{l}-.46 \\
-.55 \\
-.34\end{array}$ \\
\hline $\begin{array}{l}\text { Total: } 17 \text { facilities having } 111.731 \\
\text { to } 374,354 \text { Instrument Operations } \\
\text { each during } 1968 . \quad N \text { ATCSs }=613\end{array}$ & $\begin{array}{l}1 \\
2 \\
3 \\
4\end{array}$ & $\begin{array}{r}26.1 \\
36.5 \\
10.4 \\
5.1\end{array}$ & $\begin{array}{l}4.3 \\
5.5 \\
3.2 \\
0.7\end{array}$ & & .81 & $\begin{array}{l}.03 \\
.63\end{array}$ & $\begin{array}{l}-.35 \\
-.44 \\
-.29\end{array}$ \\
\hline
\end{tabular}

* A1l correlation coefficients are statistically significant at the .01 level except those of training entry age versus experience.

cant. Nonetheless, the findings appeared to contradict the rather widespread belief that the older and most experienced ATCSs at the more complex facilities tended to perform less well than their counterparts at relatively low-ranked installations. However, the results of the correlational analysis were deemed insufficient to fully resolve such an issue.

Additional analyses are presented in Figures 5 and 6. The data for each of the three subsamples were analyzed in much the same manner as previously shown in Figures 3 and 4 for the total group of 613 subjects. First, the RLGR means were computed and plotted by age level for the subjects within each subsample who had "12 or less" or "13 or more" years of FAA ATC experience (Figure 5). Secondly, the rating means were obtained for the ATCSs of differential experience levels represented within the dichotomized age groupings of " 40 or younger" and "41 or older."

Before considering other results stemming from these analyses, it should be noted that the subsamples, although roughly the same size, contained disproportionate numbers of the older and/or more experienced subjects. Only 95 of the 613 ATCSs, it may be recalled, were over 40 years of age. The tabular section of Figure 6 shows the distribution of the 95 among the three subsamples. Of the 95, only 19 (20 per cent) were in the High IFR Subsample, 29 (30.5 per cent) were on the ATCS staffs of installations we categorized as "Intermediate," and 47, representing 49.5 per cent of the subgroup, worked at 


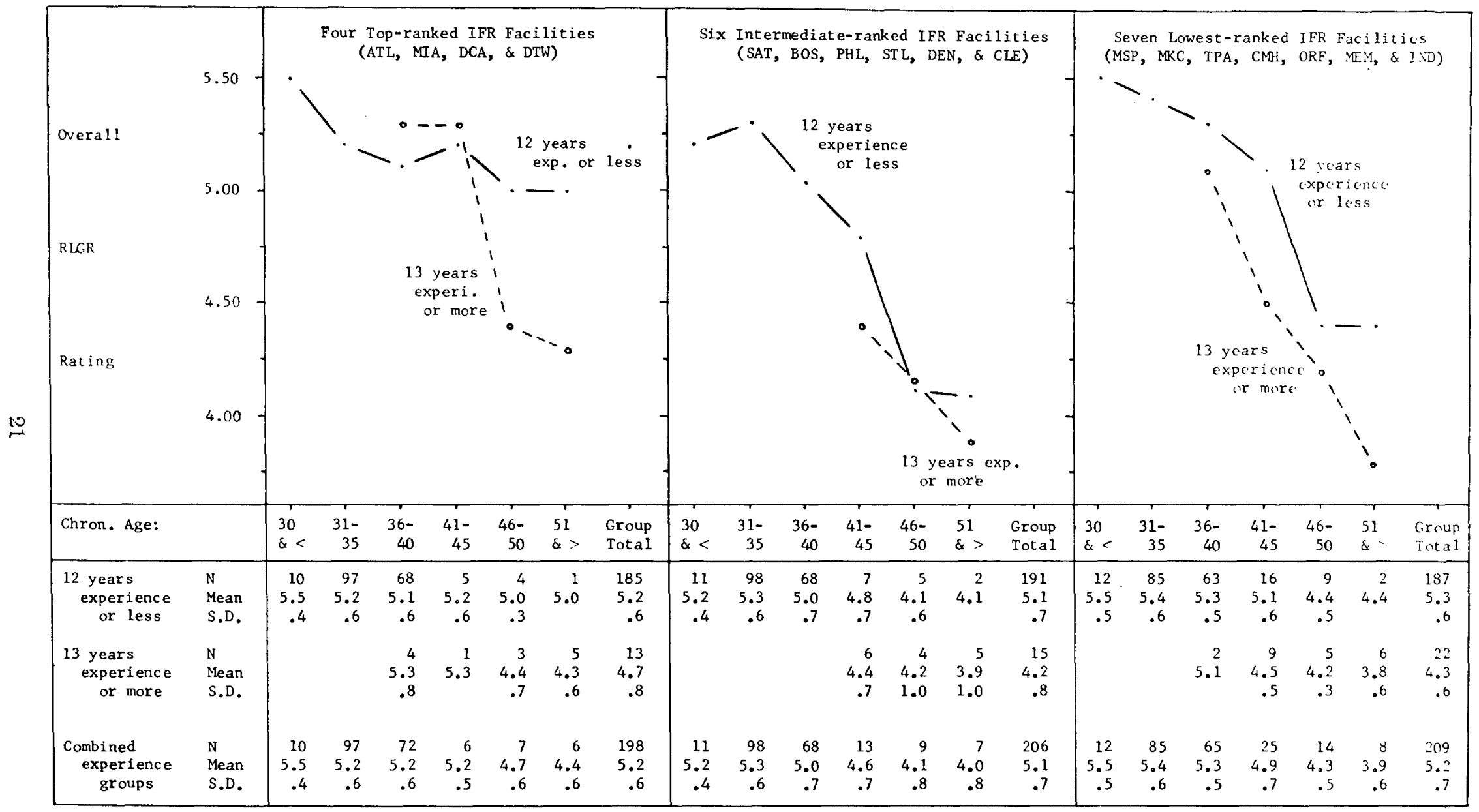

FIGURE 5. Means of Overall RLGR Ratings by age levels for dichotomized experience groups of Terminal ATCSs working in Level-III facilities having relatively high, intermediate, or low volumes of IFR traffic. 


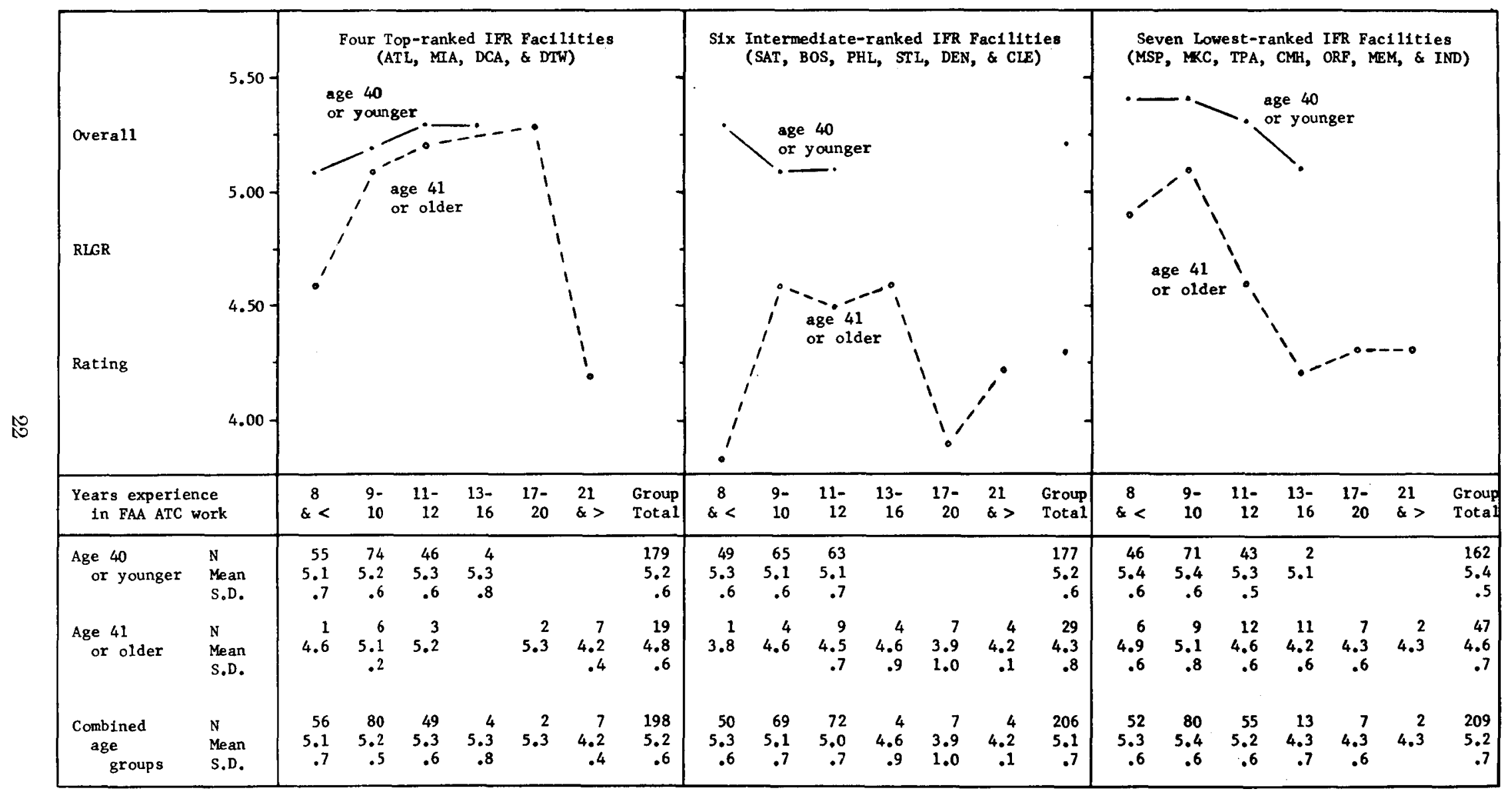

FrgURE 6. Means of Overall RLGR Ratings by experience levels for dichotomized age groups of Terminal ATCSs working in Level-III facilities having relatively high, intermediate, or low volumes of IFR traffic. 
facilities which had less than 200,000 IFR operations during FY-1969: A conventional $t$ test $^{6}$ indicated that the Low IFR Subsample included a significantly $(p<.01)$ greater proportion of the 95 older subjects than either of the other two subsamples. Also, the results of a Chi-square test $^{6}$ indicated that the proportions of the older and younger subjects in the three subsamples differed significantly $(p<.01)$ from those expected on the basis of a random distribution.

Although only 50 of the 613 subjects possessed FAA ATC experience of 13 years or more, 22 of them (44 per cent) were represented in the Low IFR Subsample, 15 (30 per cent) were stationed at "Intermediate" facilities, and only 13 (26 per cent) controlled traffic at any of the four topranked IFR installations. However, no statistically significant differences were found with regard to the distribution of the differentially experienced subjects among the three subsamples.

Quest for Explanations Why Few Older ATCSs Worked Within Highest-Ranked Facilities. The authors consulted a number of ATCoriented personnel whom they felt might be able to offer plausible explanations as to why the older and/or more experienced subjects were not proportionately distributed among the High, Intermediate, and Low Subsamples. The most cogent explanations were based on the common assumption that the complexity or difficulty of ATC work varied from facility to facility in accordance with the types and amounts of air traffic which they handled. A frequently advanced theory held that the resiliency of ATCSs to work-related stress effects generally declined with aging, which was a concomitant of experience and that, as a consequence, the screening effects (i.e., attrition rates) had probably been greatest (particularly with regard to the oldest ATCSs) at the busiest IFR facilities and progressively lower at the intermediate-ranked and lowest Level-III facilities. Several such proponents, and others with different viewpoints, speculated that many of the older and more experienced ATCSs within the lower-ranked facilities in 1969 may have represented transfers, volitional or management-induced, from higherranked Level-III Terminal facilities or from other types of facilities wherein they experienced difficulty in performing at a fully satisfactory level. It was also opined that many of the cur- rently older and/or more experienced ATCSs may always have been relatively mediocre performers, or otherwise they probably would have been promoted to positions of supervisory status (by 1969).

A. Training-Entry Age. The frequency with which the conferees alluded to training-entry age and its presumed implications prompted a comparative analysis of the subsamples with regard to the entry ages of those subjects aged 41 and older at the time the rating data were collected. In examining the frequency distributions (which are not shown in this report), the entry age of 36 was recognized as the best point on the distributions for purposes of discrimination. Only 26.3 per cent $(\mathrm{N}=5)$ of the 19 oldest subjects of the High IFR Subsample and just 24.1 per cent $(\mathrm{N}=7)$ of the 29 ATCSs of age 41 and older at the six intermediate-ranked facilities were over 35 years of age when they began their FAA ATC careers. In contrast, slightly over 40 per cent $(N=19)$ of the 47 oldest subjects of the Low IFR Subsample had entry ages of 36 and higher. None of the differences, however, were statistically significant. Moreover, had the proportion for the low Subsample been of even greater magnitude, it would not necessarily have lent support to the claim that subjects who entered the ATC system relatively late in life tended to experience less difficulty in surviving the screening hurdles at the low-ranked facilities than at intermediate or high-ranked IFR installations. (No data or information were available with which to resolve the issue.)

B. Facility Transfers. Some insight regarding the matter of transfers was obtained by examining the controllers' responses to certain items of the Personal Data and Background Form. The vast majority of the older and more experienced ATCSs within facilities of each of the three categories was found to have been involved in at least one transfer and more than half of them indicated that they had previously worked at two or more ATC installations. However, all differences between the three subgroups with respect to percentages involved in one, two, or three or more transfers were not statistically significant. It was also determined that the transfers of some subjects within each subsample had occurred five to twenty years earlier than those of others and that the facilities from which 
they transferred included Air Route Traffic Control Centers and VFR Towers, as well as TATC IFR facilities of different levels. These findings and the difficulties which would have arisen in comparing all the facilities in terms of amounts and types of traffic handled during various years led to cancellation of plans for analyses bearing upon the hypothesis that "most transfers of the older and more experienced controllers were from jobs of 'greater complexity' to those of 'lesser complexity'."

C. Mean Ratings by Age Level for the Three Subsamples. A point which warrants re-emphasis is that the vast majority of the ATC-oriented consultants postulated that the difficulty of ATC work varied from facility to facility in accordance with IFR operations. However, the analyses depicted in Figures 5 and 6 yielded no significant differences between the mean RLGR performance ratings of the three subsamples. The means were: 5.2 for the 209 ATCSs (of all age and experience groupings) of the seven lowest-ranked facilities, $\tilde{0} .1$ for the 206 representing the combined staffs of those we categorized as intermediate, and 5.2 for the 198 who handled the heaviest annual IFR traffic loads. Analyses in which the age and experience variables were dichotomized also yielded findings which were highly consistent across the three subsamples. In each subsample, the mean RLGR performance rating of those subjects having 13 or more years of FAA ATC experience was found to be significantly lower $(p<.01)$ than that of the lesser experienced subjects. Also, there was no subsample for which the mean rating of subjects aged " 41 and older" failed to be significantly lower than that established for the subjects " 40 and younger."

However, the detailed analyses in which the rating means were obtained for subjects within each of several age brackets and experience levels indicated that the relationships of both age and experience to performance were rather markedly different for the High versus the Intermediate and Low Subsamples. This is illustrated by the fact that the most unique of the three graphs shown in Figure 5 and the most unique of those presented in Figure 6 pertained to the 198 ATCSs of the four highest-ranked of the 17 IFR facilities surveyed.
Some 185 of the 198 subjects of the High IFR Subsample possessed no more than 12 years FAA ATC experience. Ten of the 185 were less than 31 years old. As shown in Figure 5, these ten received a mean performance rating of 5.5, which was only slightly higher than the rating means (of 5.2, 5.1, 5.2, 5.0, and 5.0) of their comparably experienced colleagues of the age brackets $31-35$, $36-40,41-45,46-50$, and 51 and older. Moreover, the five youngest (i.e., four of age $36-40$ and one of age 41) of the 13 subjects in the High IFR Subsample who had 13 years experience or more also received commendably high ratings, whereas the only means which were relativeiy low pertained to three of the most experienced subjects of the age bracket $46-50$ and five who were 51 or older.

Unlike those depicted for the High IFR Subsample, the plotted means (shown in Figure 5) for the Intermediate and Low IFR Subsamples reflected successively lower performance levels for the subjects of every age bracket beyond $31-35$, irrespective of experience; and the greatest of the differences between subjects of adjacent age brackets involved those 41-45 and those 46-50. The Intermediate Subsample included 15 subjects with 13 years or more FAA ATC experience; the six youngest of the 15 , in the 41-45 age bracket, received a mean rating of 4.4 which was appreciably below that of their lesser experienced colleagues of the same age bracket but slightly higher than that of their four comparably experienced coworkers of age 46-50 and considerably better than the mean rating of the five oldest of the 15 most experienced subjects. For the Low IFR Subsample, the plotted mean ratings of the 22 ATCSs who had 13 years experience or more tended to parallel those of the 187 less experienced controllers; most differences between the means of the differentially experienced subgroups of the various age brackets were rather small and, more importantly, there was no age interval in which the subjects of the upper experience category received a higher mean rating than their coworkers of the lower experience category.

Although not shown, the correlations between age and performance were obtained for the experience subgroups of the separate and combined subsamples. Correlations between the two variables for subjects of the lower experience category were $-.13,-.35$, and -.36 for the High, 
Intermediate, and Low Subsamples, respectively, and -.28 for the combined subsamples. Corresponding correlations for the ATCSs having 13 years experience or more were $-.68,-.51$, and -.61 , with the combined subsamples yielding a correlation of -.58 .

Figure 6 presents a comparative analysis of the three subsamples with respect to the performance means of the subjects aged " 40 or younger" and " 41 or older" within each of six length-of-experience subgroupings (i.e., "8 years or less," "9-10," "11-12," "13-16," "17-20," and "21 years or more"). Looking first at the plotted means of the younger subjects only, it should be noted that all differences between the experience subgroups, within and between the three subsamples, are relatively minor and, though there is little similarity between the patterns of the plotted means, the results for each of the subsamples indicate no more than a negligible relationship between their ratings and experience.

The rating means shown in Figure 6 for the ATCSs of age 41 and older of the high-, intermediate-, and low-ranked installations reflect a high degree of variability, with most of the lower means pertaining to those having the greater amounts of experience. The means for all but eight of the 198 ATCSs who worked at the four busiest IFR facilities were, as mentioned earlier, commendably high; the mean rating for seven of the eight, all of whom were over 40 years old, was 4.2 , which was significantly lower (probabilities ranged from .01 to .05 ) than the mean ratings of both the younger and older ATCSs of most other experience levels. In comparing the means by experience level for the 29 older subjects of the Intermediate Subsample, two of the three lowest means were found to pertain to subgroups having over 16 years experience. Of the 47 older subjects in the Low IFR Subsample, six with experience of eight years or less received evaluations averaging 4.9 and nine with ATC service of 9-10 years received a mean rating of 5.1, whereas those having progressively greater amounts of experience were generally rated much lower. More importantly, there was no subsample in which the subjects of age 41 and older of any experience level received a mean rating greater than that of the younger (comparably experienced) subjects. The older subjects within some of the experience subgroups of the High IFR Subsample received mean rat- ings which were only slightly lower than those of their younger coworkers. Most remaining differences, however, were of appreciable magnitude and some were statistically significant although at least one of the two means in each instance was based on a very small number of cases.

Correlations (not shown) between the ungrouped experience data and performance ratings of the subjects aged 41 and older were $-.62,-.15$, and -.40 for the High, Intermediate, and Low Subsamples, respectively, and -.34 for those of the combined subsamples. Corresponding coefficients for the younger subjects were $.07,-.07$, and -.04 for the High, Intermediate, and Low Subsamples, and .00 (zero) for those of the combined subsamples. The experience and performance variables were not expected to be highly related for the younger subjects because few of them were of sufficient age to have permitted the attainment of lengthy experience. Even with such restriction-of-range effects, however, correlations much greater than those actually obtained would have been theoretically possible.

Findings for Combined Intermediate and Low Subsamples Only. In the last series of analyses undertaken in the study, intercorrelations were obtained between age, experience, and performance for the combined Intermediate and Low Subsamples only. The correlation between age and performance was -.34 for the 378 subjects who had 12 years experience or less, -.54 for the 37 with 13 years or more, and -.50 for the merged experience subgroups. The r's for experience versus performance were $-.03,-.32$, and -.33 , respectively, for the 339 subjects of age 40 and younger, the 76 of age 41 and older, and the 415 of all ages. A coefficient of .62 reflected the relationship of experience to age for the total group (of all subjects of the Intermediate and Low Subsamples).

A regression analysis, in which the variance common to both the age and experience variables was determined, revealed that Experience (for which a validity coefficient of -.33 had been obtained for the combined Intermediate and Low Subsamples) would have correlated -.03 with performance had the 415 subjects been of identical age. However, after extraction of the variance associated with Experience, the age variable 
(which had correlated -.50 with performance) was found to have a residual validity of -.39 . In other words, the correlation between Age and performance would have been -.39 had there been no variability in the experience of the 415 subjects of the two subsamples.

Although relatively few of the older ATCSs controlled traffic at the four busiest IFR facilities, the results depicted in Figures 5 and 6 , supplemented by those obtained in the correlational analyses, suggest that the proficiency of ATCS personnel at TATC IFR facilities is generally more apt to decline as a result of unknown factors associated with aging than as a consequence of presumed effects stemming from lengthy experience.

\section{Summary and Conclusions.}

Several findings emerging from this study of 613 journeyman-level ATCSs of 17 Level-III TATC facilities were remarkably like those obtained in a previous and highly similar study ${ }^{1}$ of over 500 journeymen controllers of four Air Route Traffic Control Centers. Both investigations revealed that the majority of the controllers were under 36 years of age and/or possessed FAA ATC experience of less than 11 years at the time their experimental ratings of job performance were collected. Notwithstanding such restriction-of-range effects, however, both studies provided convincing evidence of inverse relationships between the chronological ages and job performance evaluations of ATCS personnel. Although an inverse relationship was also obtained in each study between performance and length of ATCS experience, the predictive potential of the latter was not nearly as great as that of age, and its influence was virtually nil after extraction of the variance associated with age.

In the ARTCC study, as in the present investigation, an examination of the rating means by age grouping indicated that the highest of the averages pertained to the ATCSs of age 30 and younger whereas the means for controllers of age 31-35 and of each succeeding five-year age bracket were progressively lower, with the greatest decrements pertaining to those of the age subgroups $36-40,41-45$, and 46 and older. A comparative analysis of the rating means by experience level for the ARTCC specialists re- vealed negligible differences only between all subgroups having six to ten years experience, whereas the average rating for the most experienced subgroup, comprised of only 18 subjects having 11 years service or more, was lower, yet not appreciably lower, than that of each of the lesser experienced subgroups. Inasmuch as the experience of the TATC subjects covered a greater range than that represented by the ARTCC sample, the results stemming from the corresponding analysis of the TATC data should be considered more meaningful and reliable than the former. The results reflected a high degree of comparability between the performance levels of the TATC subgroups having $5-6,7-8$, or $9-10$ years experience and also between each of the latter and the subgroup with 11-12 years service; however, the respective means of those having $13-16,17-20$, and 21 or more years experience were contrastingly lower and each differed significantly (at either the .05 or .01 level) from those obtained for lesser experienced subgroups.

Only 12.5 per cent $(\mathrm{N}=66)$ of the 526 ARTCC specialists were over 40 years old at the time their rating data were collected in 1965, less than 4 per cent $(\mathrm{N}=21)$ of the 526 had more than 10 years experience, and 15 of the 21 were among the 66 who were 41 years of age or older. Ninetyfive of the 613 TATC subjects, or 15.5 per cent, were 41 or older when rated in late 1968 or early 1969 ; almost 37 per cent $(\mathrm{N}=226)$ had at least 11 years FAA ATC experience, 50 of the 613 , or 8.2 per cent, had 13 years or more, and 44 of the latter 50 were also among the 95 who were over 40 years old. Assuming that the samples were at least somewhat representative of the FAA's ATCS population, these data suggest that, even at this time (1973), only a small minority of the controllers within the entire Air Traffic Management System are over 40 years of age and/or possess experience of more than 12 years. This does not, however, relegate to unimportance the findings relating to such older and more experienced personnel.

The Pearson product-moment correlations obtained in the present study between performance and both age and experience for the total sample of 613 TATC subjects should be regarded, like those reported in the ARTCC study, as being grossly attenuated. In other words, they probably represent gross underestimates of the in- 


\section{REFERENCES}

1. Cobb, B. B.: The Relationships Between Chronological Age, Length of Experience, and Job Performance Ratings of Air Route Traffic Control Specialists. FAA Office of Aviation Medicine Report No. AM67-1, 1967.

2. Cobb, B. B., C. D. Lay, and N. M. Bourdet: The Relationship Between Chronological Age and Aptitude Test Measures of Advanced-Level Air Traffic Control Trainees. FAA Office of Aviation Medicine Report No. AM-71-36, 1971.

3. Cobb, B. B., and J. J. Mathews: A Proposed New Test for Aptitude Screening of Air Traffic Controller Applicants. FAA Office of Aviation Medicine Report No. AM-72-18, 1972.

4. Cobb, B. B., J. J. Mathews, and C. D. Lay: A Comparative Study of Female and Male Air Traffic Controller Trainees. FAA Office of Aviation Medicine Report No. AM-72-22, 1972.

5. Glaser, R. (Ed.) : Training Research and Education, Pittsburgh, Lniversity of Fittsburgh Press, 1962.

6. MeNemar, Q.: Psychological Statistics, New York, John Wiley and Sons, 1962.

7. Miner, J. B.: Personnel and Industrial Relations: $A$ Managerial Approach, New York, The Macmillan Company, 1969.

8. Smith, R. C., B. B. Cobb, and W. E. Collins: Attitudes and Motivational Factors in Terminal Area Traffic Control Work. FAA Office of Aviation Medicine Report No. AM-71-30, 1971.

9. Tiffin, J., and E. J. McCormick: Industrial Psychology, Englewood Cliffs, New Jersey, Prentice-Hall, Inc., 1958.
10. Trites, D. K.: Problems in Air Traffic Management: I. Longitudinal Prediction of Effectiveness of Air Traffic Controllers. FAA Civil Aeromedical Research Institute Report No. 61-1, 1961.

11. Trites, D. K.: Problems in Air Traffic Management: VI. Interaction of Training-Entry Age With Intellectual and Personality Characteristics of Air Traffic Control Specialists. FAA Civil Aeromedical Research Institute Report No. 65-21, 1965.

12. Trites, D. K., and B. B. Cobb: Problems in Air Traffic Management: III. Implications of Age for Training and Job Performance of Air Traffic Controllers. FAA Civil Aeromedical Research Institute Report No. 62-3, 1962.

13. Trites, D. K., and B. B. Cobb: Problems in Air Traffic Management: IV. Comparisons of PreEmployment, Job-Related Experience With Aptitude Tests as Predictors of Training and Job Performance of Air Traffic Control Specialists. FAA Civil Aeromedical Research Institute Report No. 63-31, 1963.

14. Trites, D. K., and B. B. Cobb: CARI Research on Air Traffic Control Specialists: Age, Aptitude, and Experience as Predictors of Performance. FAA Civil Aeromedical Research Institute, Unnumbered Report, 1964.

15. Whisler, T. L., and S. F. Harper (Eds.) : Performance Appraisal, Research, and Practice, New York, Holt, Rinehart, and Winston, 1962. 

Appendix 1. Evaluation form $f r o m$ which the Radar (R), Local (L), General (G), Relative Profictency $(R)$, and overall Ratings were derived.

\section{ATCS PERFORMANCE EVALUATION FORM}

Name of ATCS being rated

Facility

In evaluating the subject employee, try to consider his performance during the busier periods as much as possible. Please try to be realistic in making your ratings. Everyone can't be average or excellent in everything.

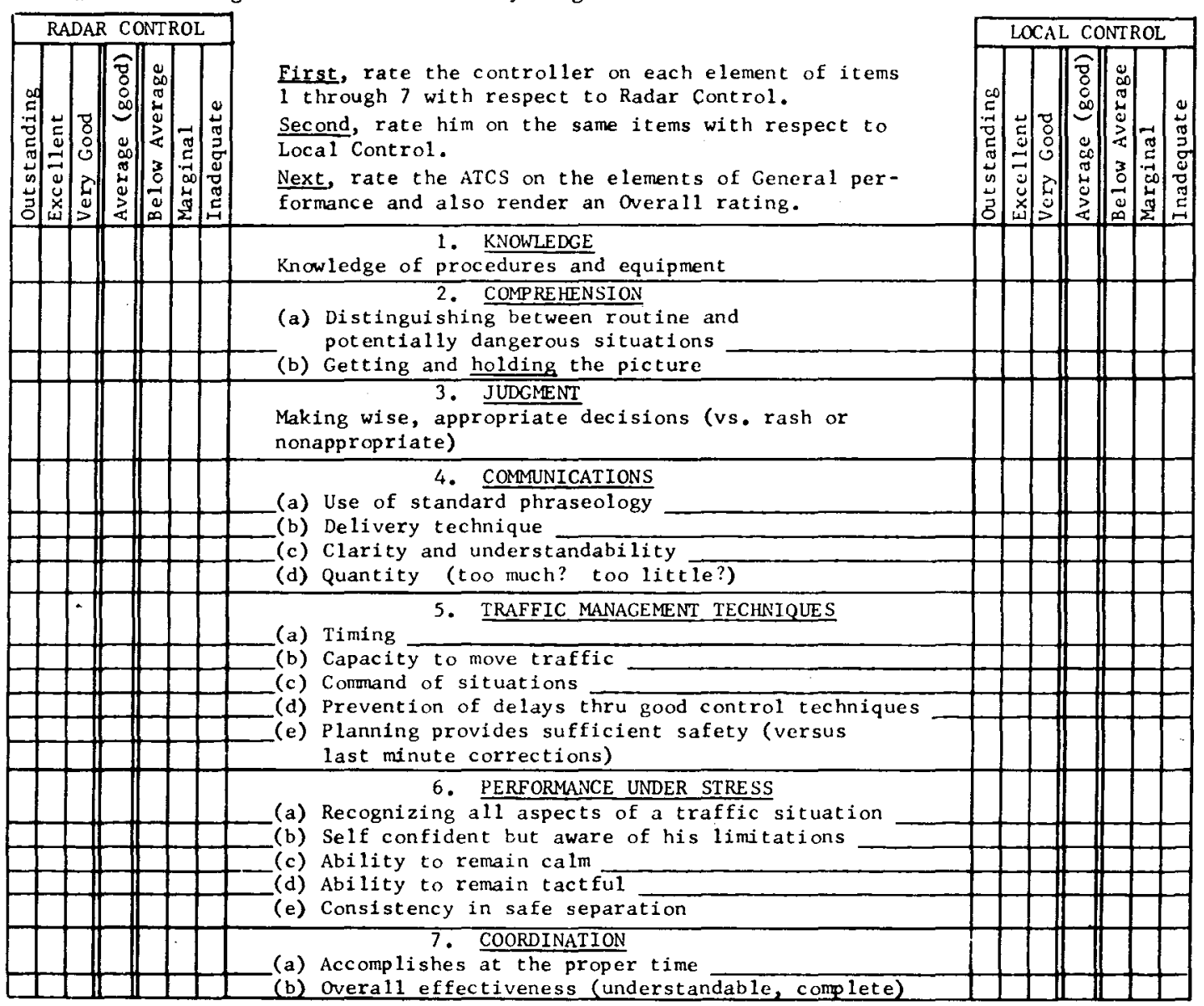

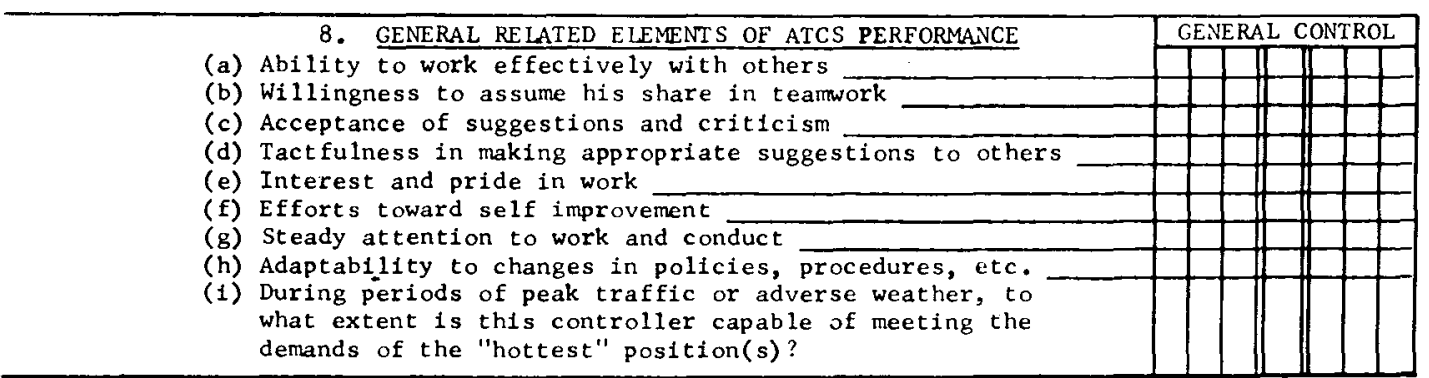

9. OVERALL RELATIVE RATING Use the scale below to rate the overall proficiency of this controller relative to all the controllers you have known. (Indicate your rating by placing a check mark in the appropriate box.)

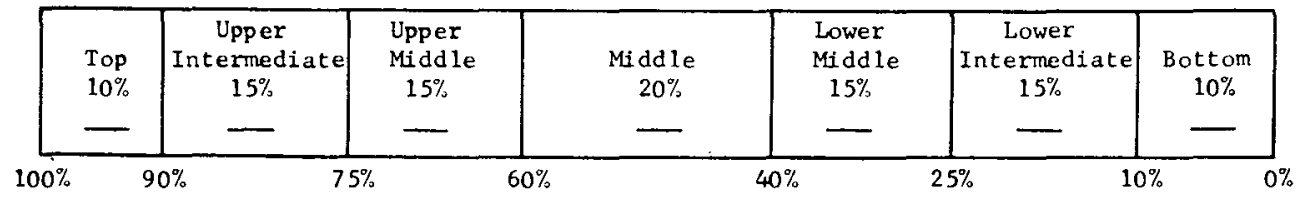


Append1x 2. Means of RLGR Rat1ngs rendered by Supervisors of three age groups on ATCSs of various age 1evele.

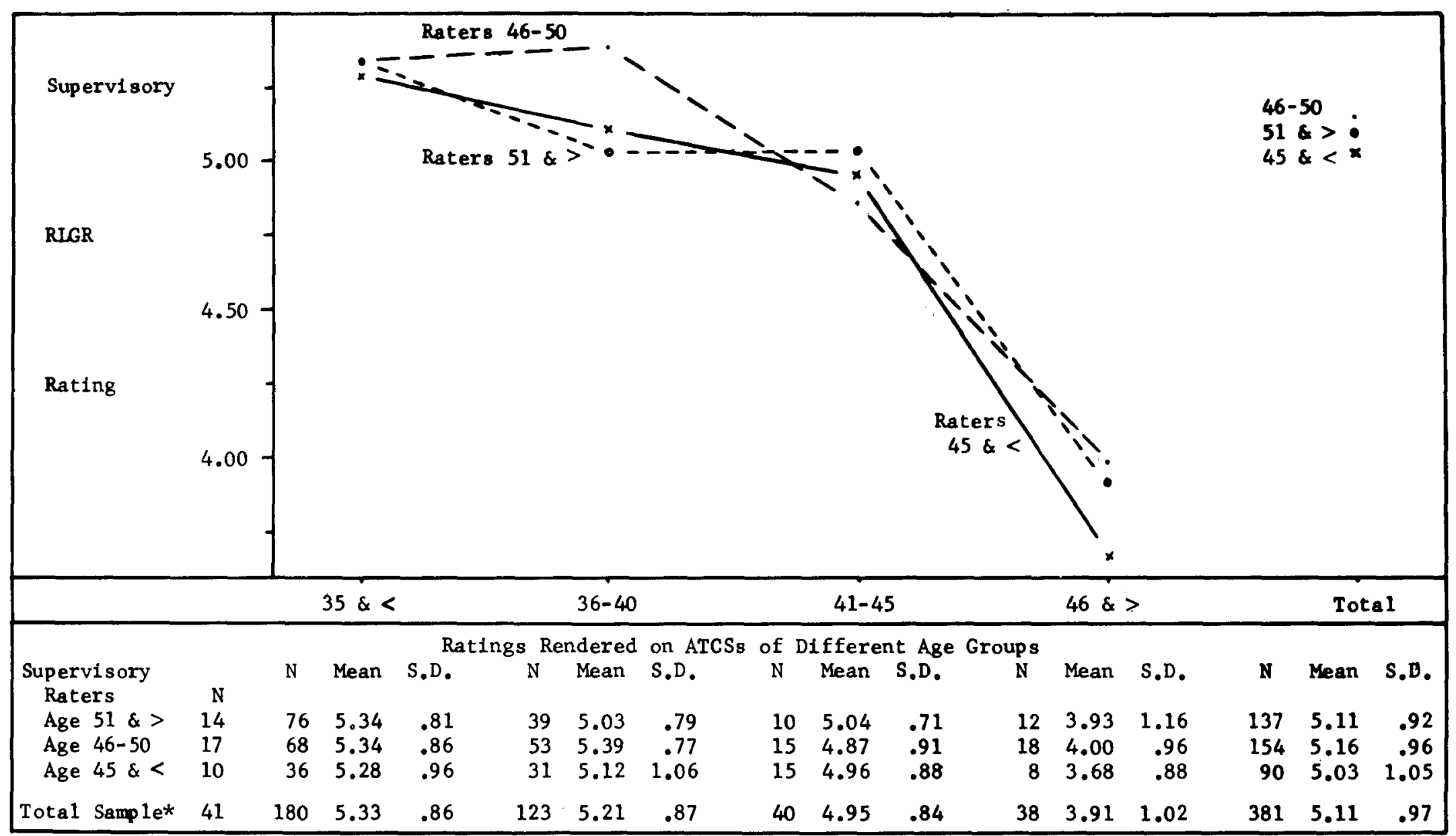

*The data pertain to the RLGR Ratings obtained at several facilities fram 41 Supervisors who deferred the anonymity privilege. The means of the ratings rendered by Supervisors of each of the age categories on ATCSs of the three youngest subgroups were significantly higher ( $p$ - . 05) than their mean evaluat lons of ATCSs over 45 years of age, whereas they made no significant differentiation between any of the three younger groups. Within each of the four ratee groups, none of the differences between the rating means proved statistically significant. 
Appendix 3. Means of RLGR Ratings rendered by Crew Chiefs of three age groups on ATCSs of various age levels.

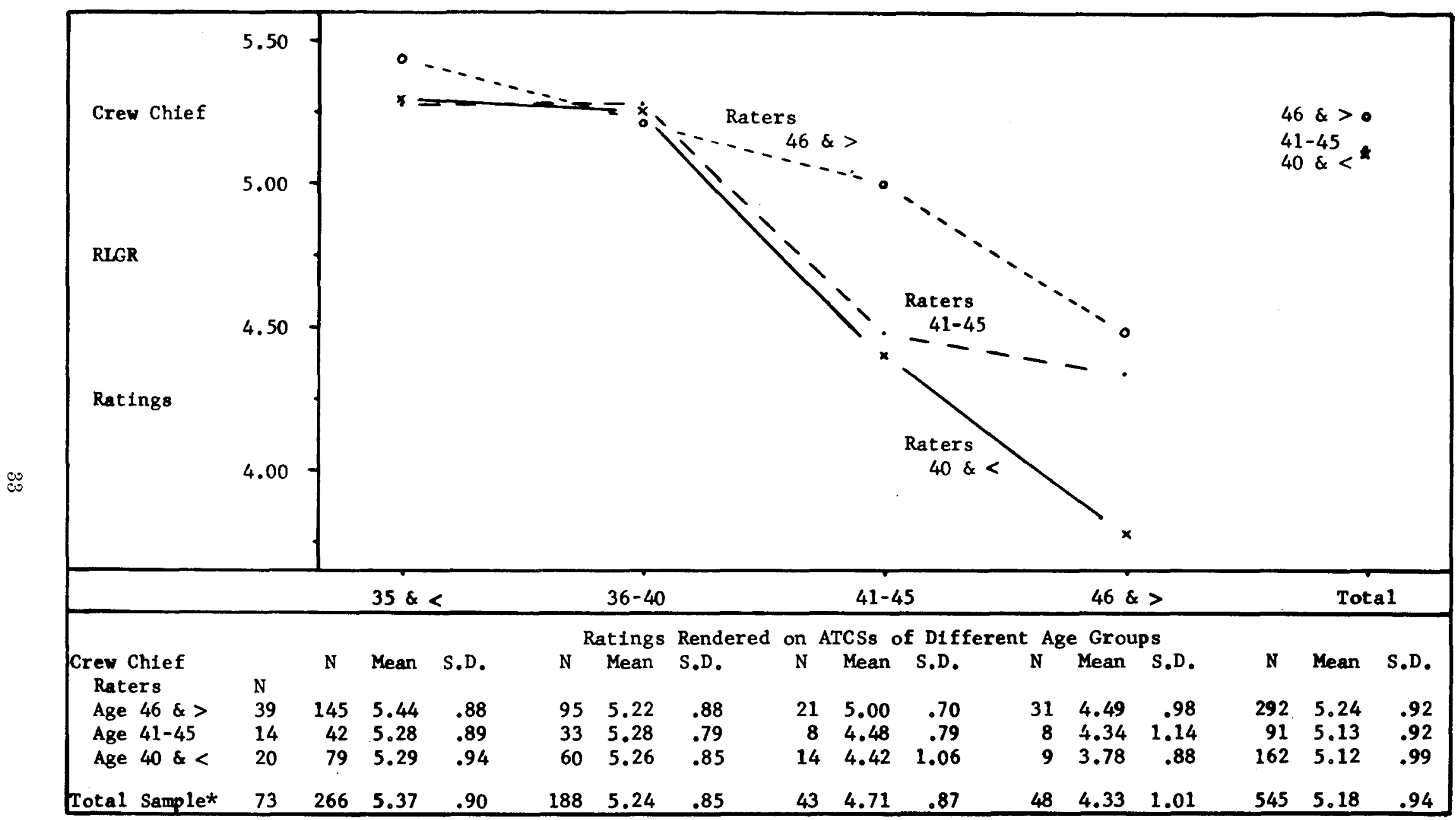

*The data pertain to ratings obtained at several facilities from 73 Crew Chlefs who deferred the anonymity privilege. The mean of ratings rendered on ATCSs of the oldest group by Crew Chiefs of age 46 and older was significantly lower ( $R<.05)$ than those rendered by the same group on controllers of elther age 35 and younger or 36-40. No 8 ignificant differences in the means of ratings recelved by the four controller age groups were found for raters of age 41-45. The Crew Chlefs of age 40 and younger rated the oldest group and those 46-50 significantly lower ( $<<.05$ ) than either of the two younger groups. Within the ratee age groups, no significant differences were found between the mean ratings rendered by the three groups of Crew Chiefs. 
Appendix 4. Means of RLGR Rat1ngs rendered by ATCSs of three age groups on ATCS peers of various age levels.

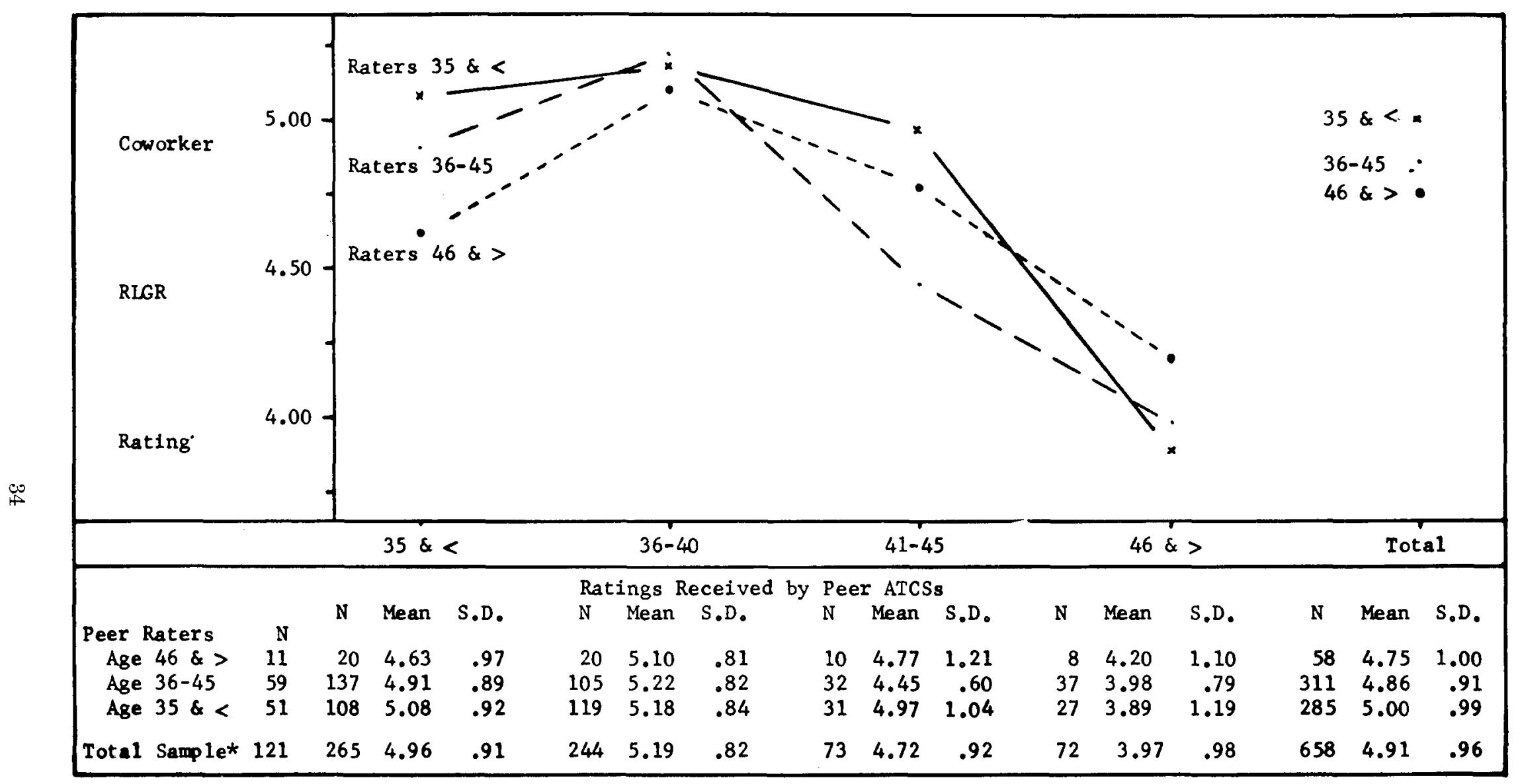

*The data pertain to the RLGR Ratings obtained at several facilities from 121 ATCSs who deferred the anonymity privilege. Each of the 121 rated four to seven peers, resulting in a total of 654 ratings from 145 ATCSs. The mean of ratings rendered by ATCSs of age 35 and younger for coworkers of age 41 to 45 was significantly higher ( $<<.05$ ) than the mean of performance evaluations of the same group of ATCSs of age 36 to 45; no other mean RLGR difference within any ratee age group proved to be significant. The means of ratings by ATCSs of age 35 and younger for controllers under 36 and those 36 to 45 were significantly higher $(p<.01)$ than their mean rating of peers 46 and older. The same was true with respect to ATCS raters aged 36 to 45 ; moreover, the latter also tended to rate ATCSs of age 41 to 45 significantly lower $(p<.05)$ than those of all lower age brackets. A comparison of ratings gubmitted by the very sma 11 number of ATCSs over 45 years of age revealed no significant mean differences between the ratee age groups. 
Appendix 7. Meanst of Crew Chief RLGR Ratings by age level for Termina 1 ATCSs of dichotomized FAA ATC experience groups "12 years or less" and "13 years or more."

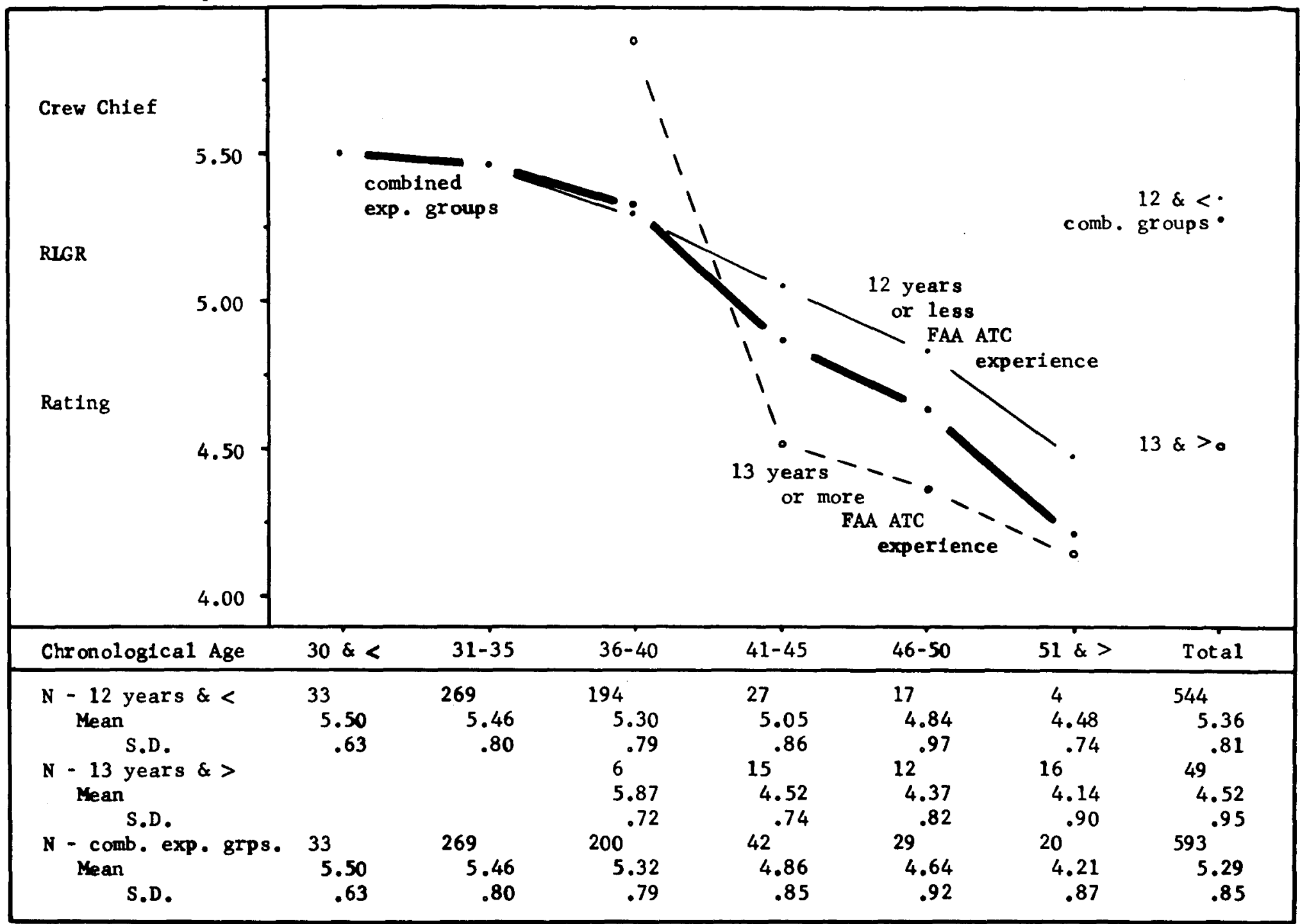

*Disregarding experlence, differences between the mean ratings of each of the following groups are significant $(p<.05)$ : ATCS s of either age 30 and younger, $31-35$, or $36-40$ versus those either 41-45, 46-50, or 51 and older. None of the differences between experience subgroups within age levels are significant. 
Appendix 8. Means* of Crew Chtef RLGR Ratings by FAA ATC experience level for Terminal ATCSs of dichotomized age groups " 40 and younger" and "41 and older."

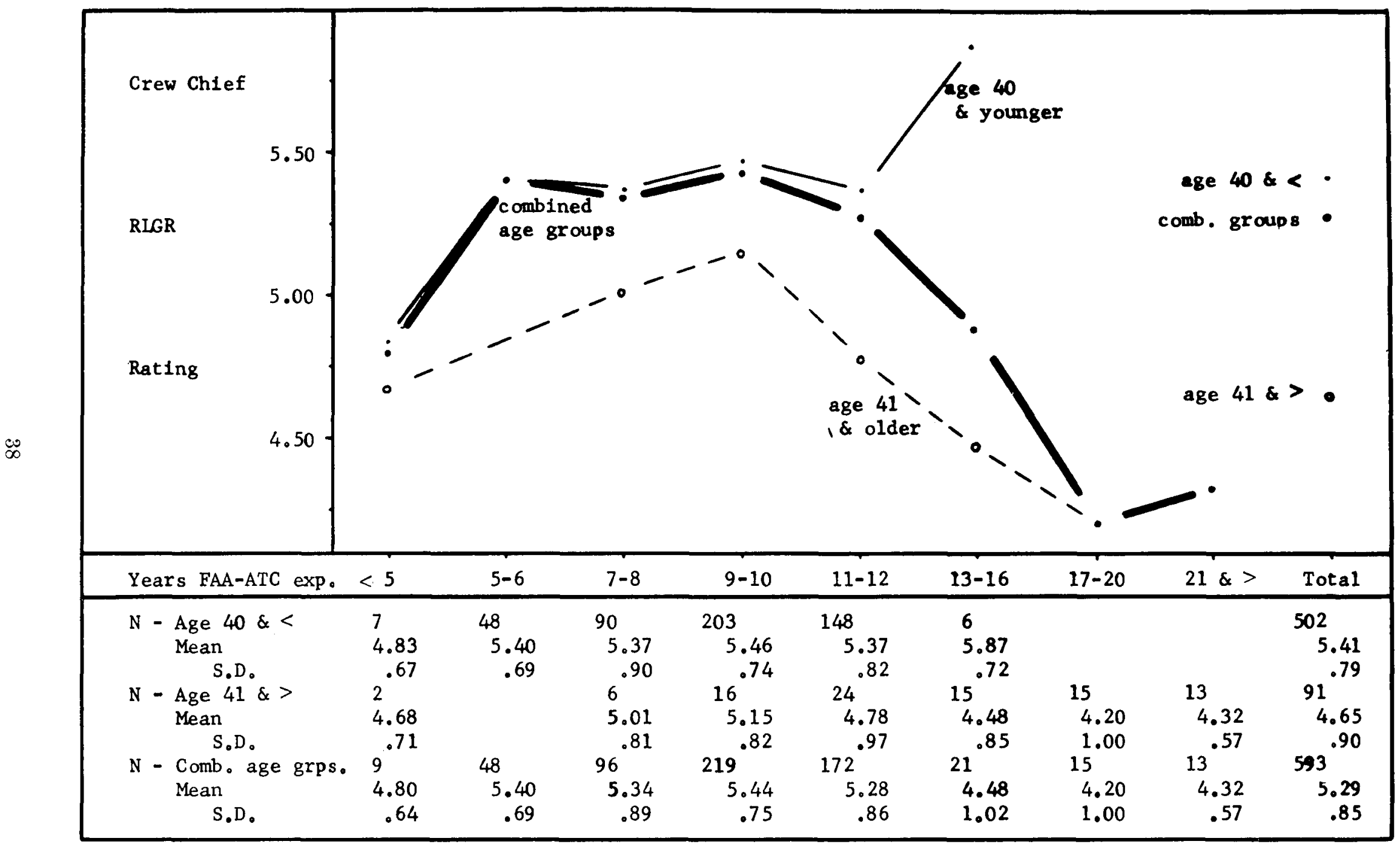

*In comparing the mean ratings of the experience groups, irrespective of age, differences are significant (p<.05) for: ATCSs having either 5-6, 7-8, 9-10, or 11-12 years experience versus those having either 17-20 or 21 or more years. For age subgroups within tenure levels, significant differences pertain to ATCSs with 11-12 and $13-16$ years experience. 
Appendix 9. Means* of Coworker RLGR Ratings by age level for Terminal ATCSs of dichotomized FAM ATC experience groups " 12 years or less" and " 13 years or more."

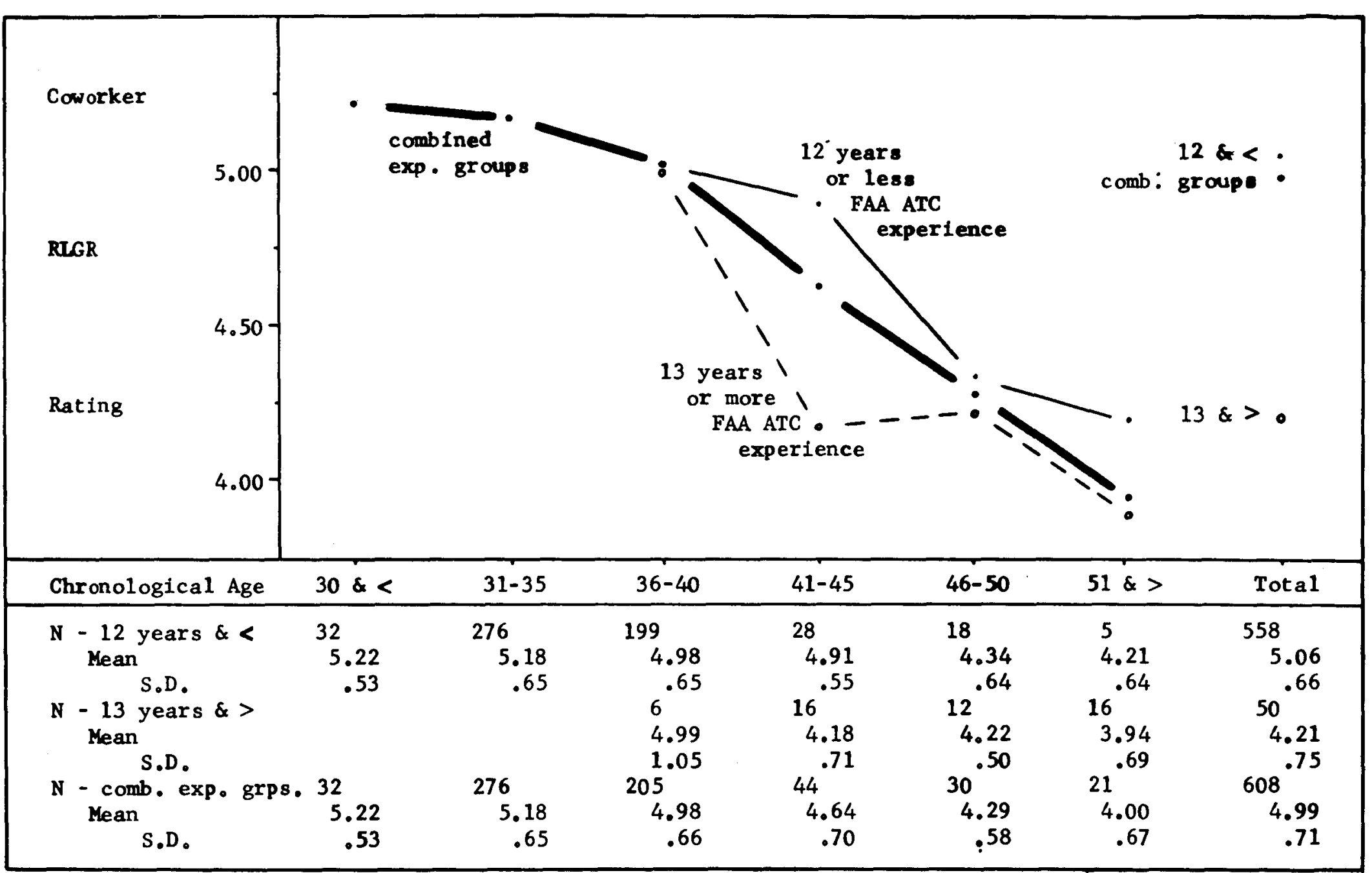

*Disregarding experience, differences between the mean ratings of each of the following groups are significant ( $\mathrm{p}<.05)$ : ATCSs of age 30 and younger versus those either 41-45, 46-50, or 51 and older; those of age 31-35 versus those either 36-40, 41-45, 46-50, or 51 and older; those of age 36-40 versus those either 46-50 or 51 and older; and those of age 41-45 versus the oldest group. Of the differences between experience subgroups within age levels, only that pertaining to ATCSs of age 41-45 is significant. 
Appendix 10. Means* of Coworker RLGR Ratings by FAA ATC experience level for Terminal ATCSs of dichotomized age groups "40 and younger" and "41 and older."

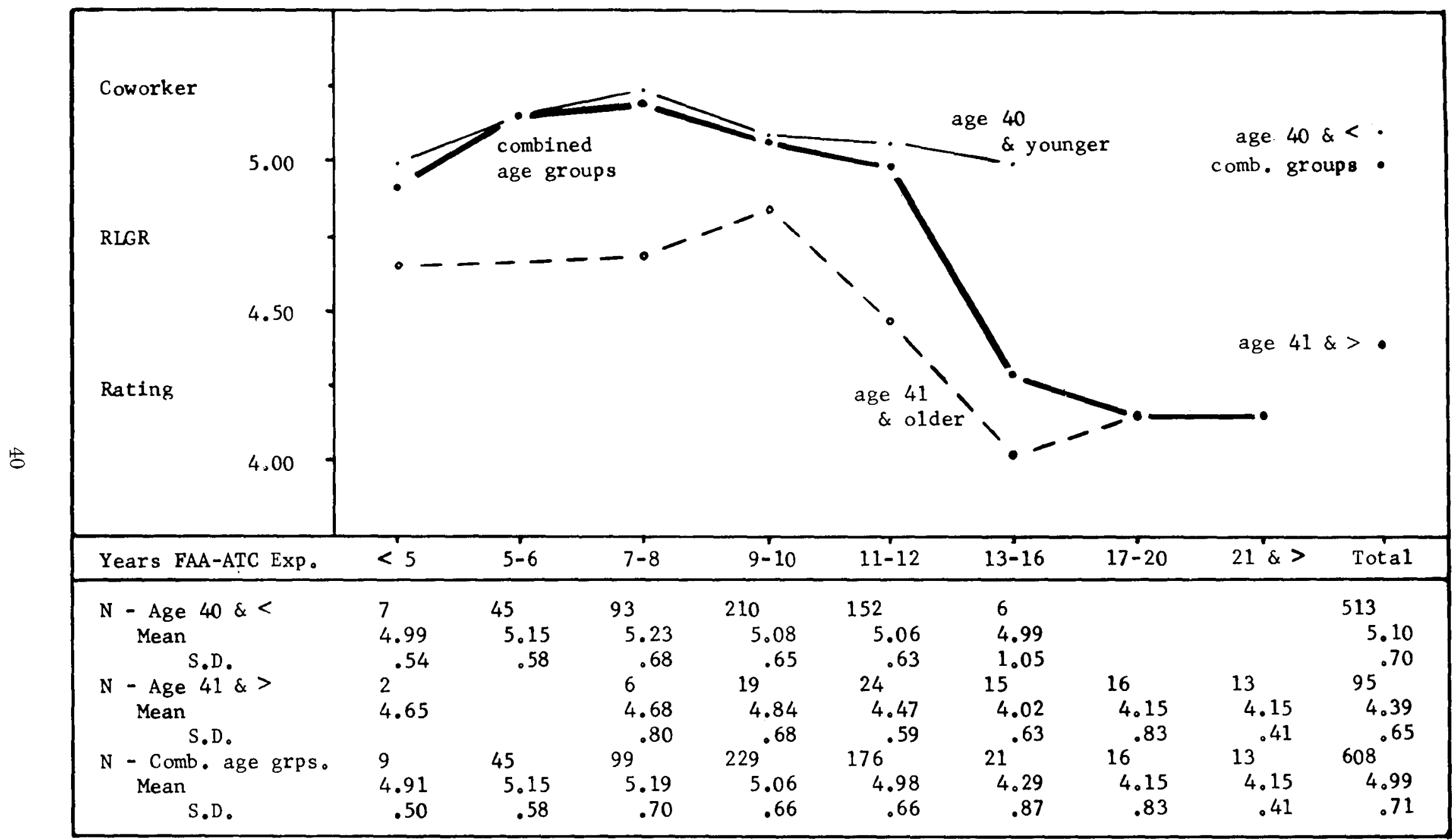

*In comparing the mean ratings of the experience groups, irrespective of age, differences are significant $(\mathrm{p}<.05)$ for: ATCSs having either $5-6,7-8,9-10$, or $11-12$ years experience versus those having either 13-16, $17-20$, or 21 or more years. For age subgroups within tenure levels, significant differences pertain to ATCSs with 11-12 and 13-16 years experience. 
Appendix 11. Means* of Overall Radar Ratings by age level for Terminal ATCSs of dichotomized FAA ATC experience groups "12 years or less" and " 13 years or more."

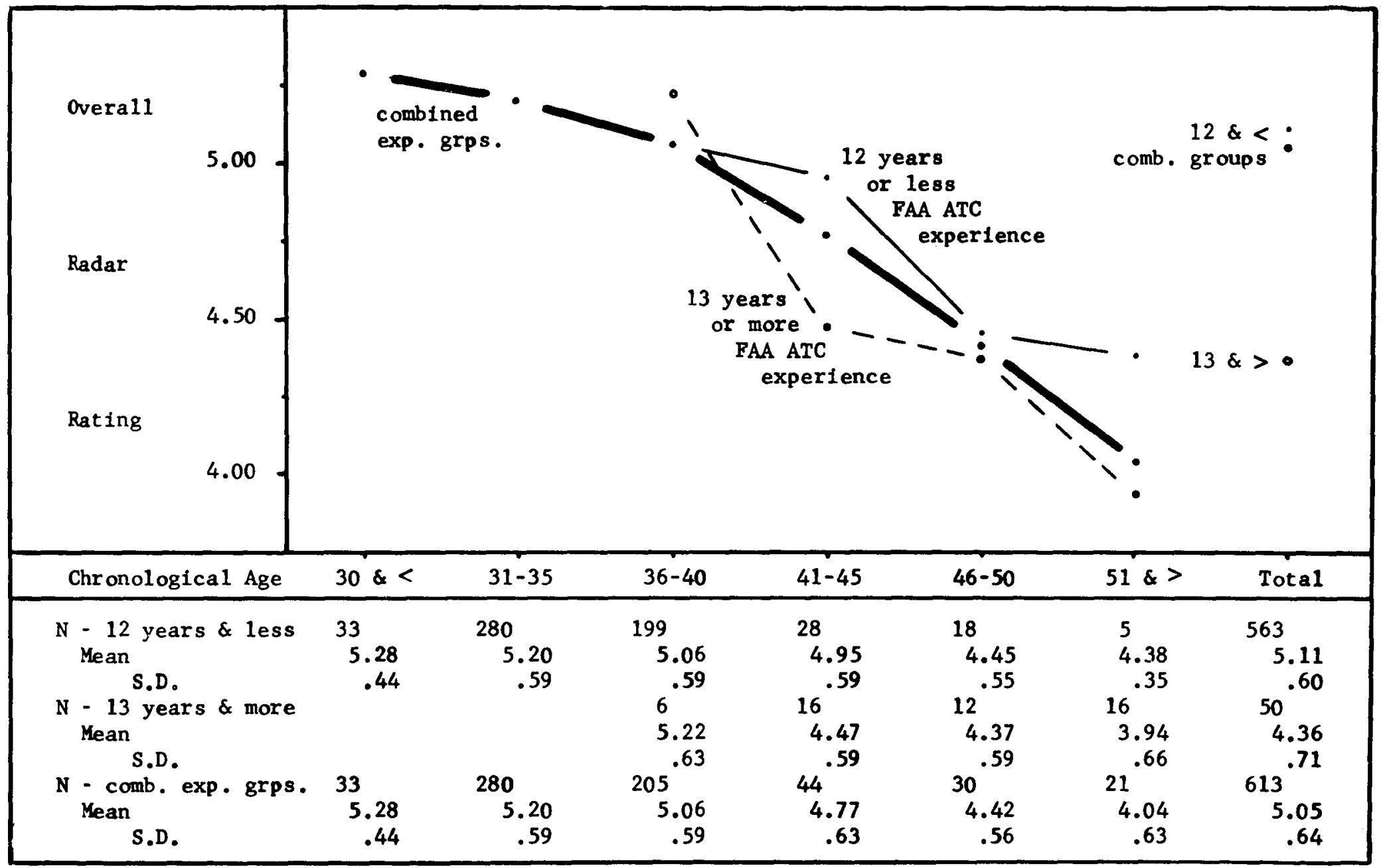

*Disregarding experience, differences between the mean ratings of each of the following groups are 8 ignificant $\left(p_{<} .05\right)$ : ATCS of either age 30 and younger or $31-35$ versus those either $41-45$, 46-50, or 51 and older; those of age $36-40$ versus those either $46-50$ or 51 and older; and those of age $41-45$ versus the oldest group. Of the differences between experience subgroups within age levels, only that pertaining to ATCSs of age 41-45 is significant. 
Appendix 12. Means* of Overa11 Radar Ratings by FAA ATC experience level for Terminal ATCSs of dichotomized age groups "40 and younger" and "41 and older."

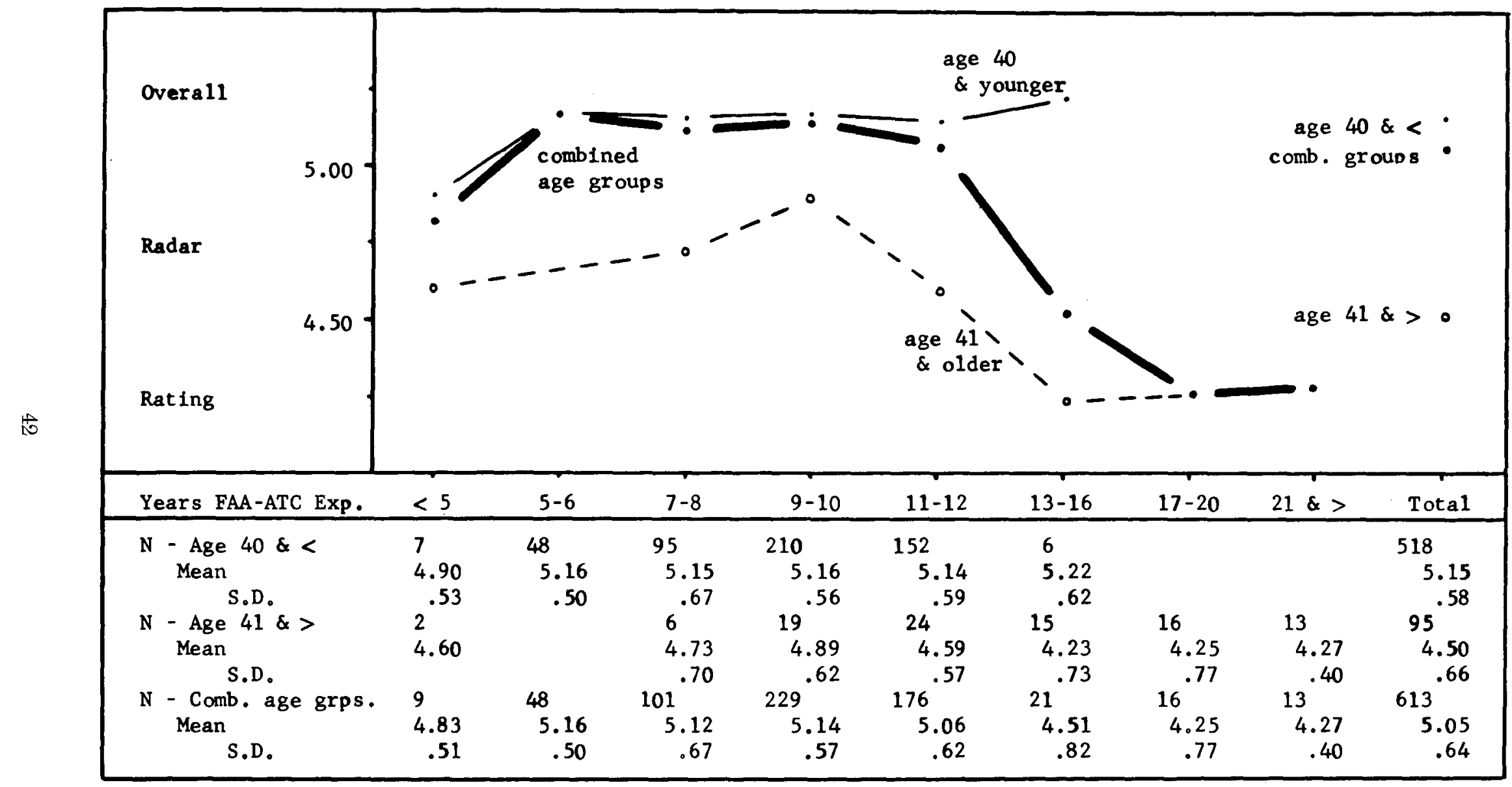

*In comparing the mean ratings of the experience groups, trrespective of age, differences are significant ( $\mathrm{p}<.05)$ for: ATCSs having either $5-6,7-8,9-10$, or $11-12$ years experience versus those having either 13-16, 17-20, or 21 or more years. For age subgroups within tenure levels, significant differences pertain to ATCSs with $9-10,11-12$, and $13-16$ years experience. 
Appendix 13. Means* of Overall Local Ratings by age leve1 for Terminal ATCS of dichotomized FAA ATC experlence groups "12 years or less" and "13 years or more."

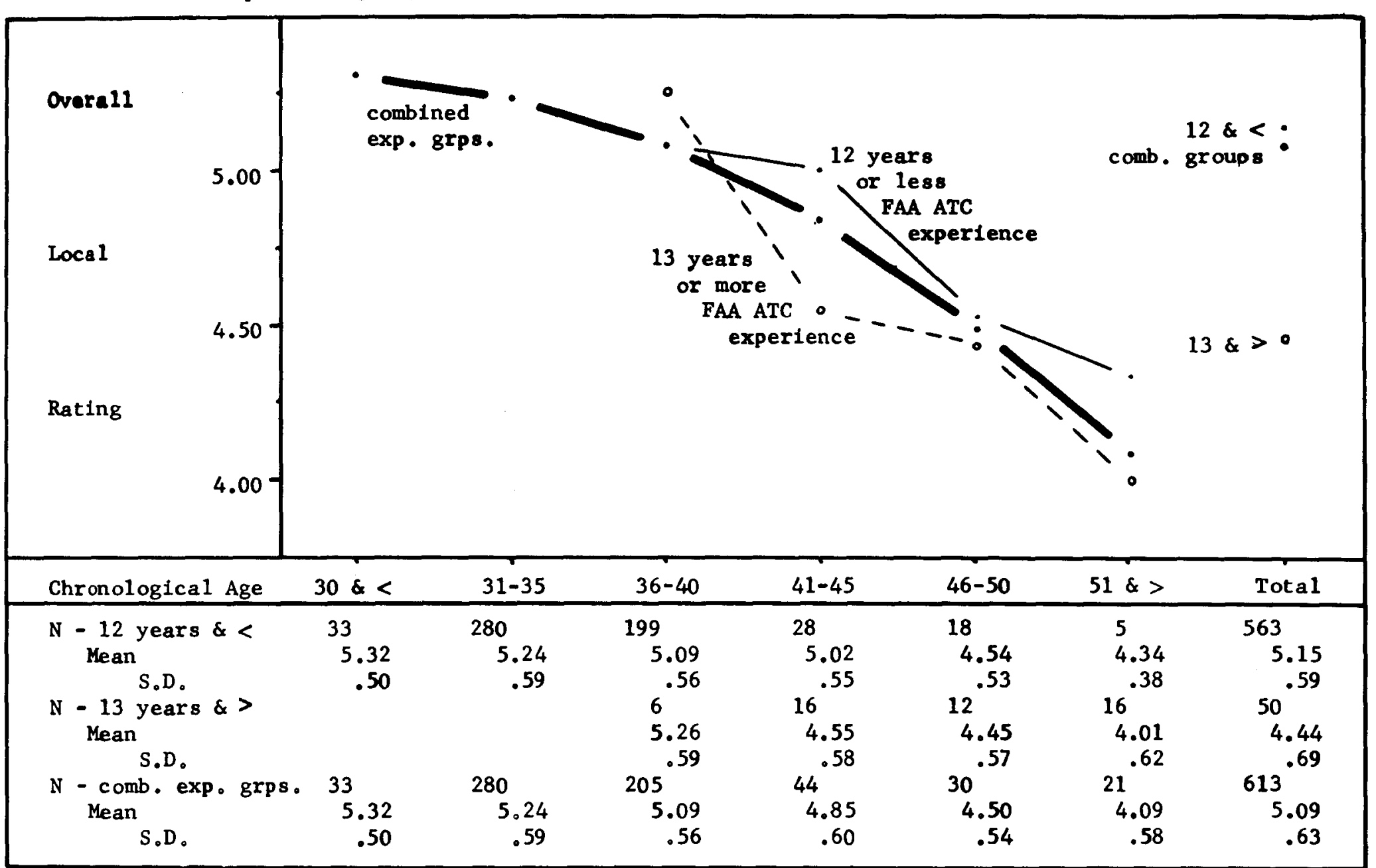

*Disregarding experience, differences between the mean ratings of each of the following groups are significant ( $\mathrm{p}<.05)$ : ATCSs of elther age 30 and younger or $31-35$ versus those either $41-45$, 46-50, or 51 and older; those of age $36-40$ versus those either $46-50$ or 51 and older; and those of age $41-45$ versus the oldest group. Of the differences between experience subgroups within age levels, only that pertaining to ATCSs of age 41-45 is significant. 
Appendix 14. Means* of Overall Local Ratings by FAA ATC experience level for Terminal ATCSs of dichotomized age groups "40 and younger" and "41 and older."

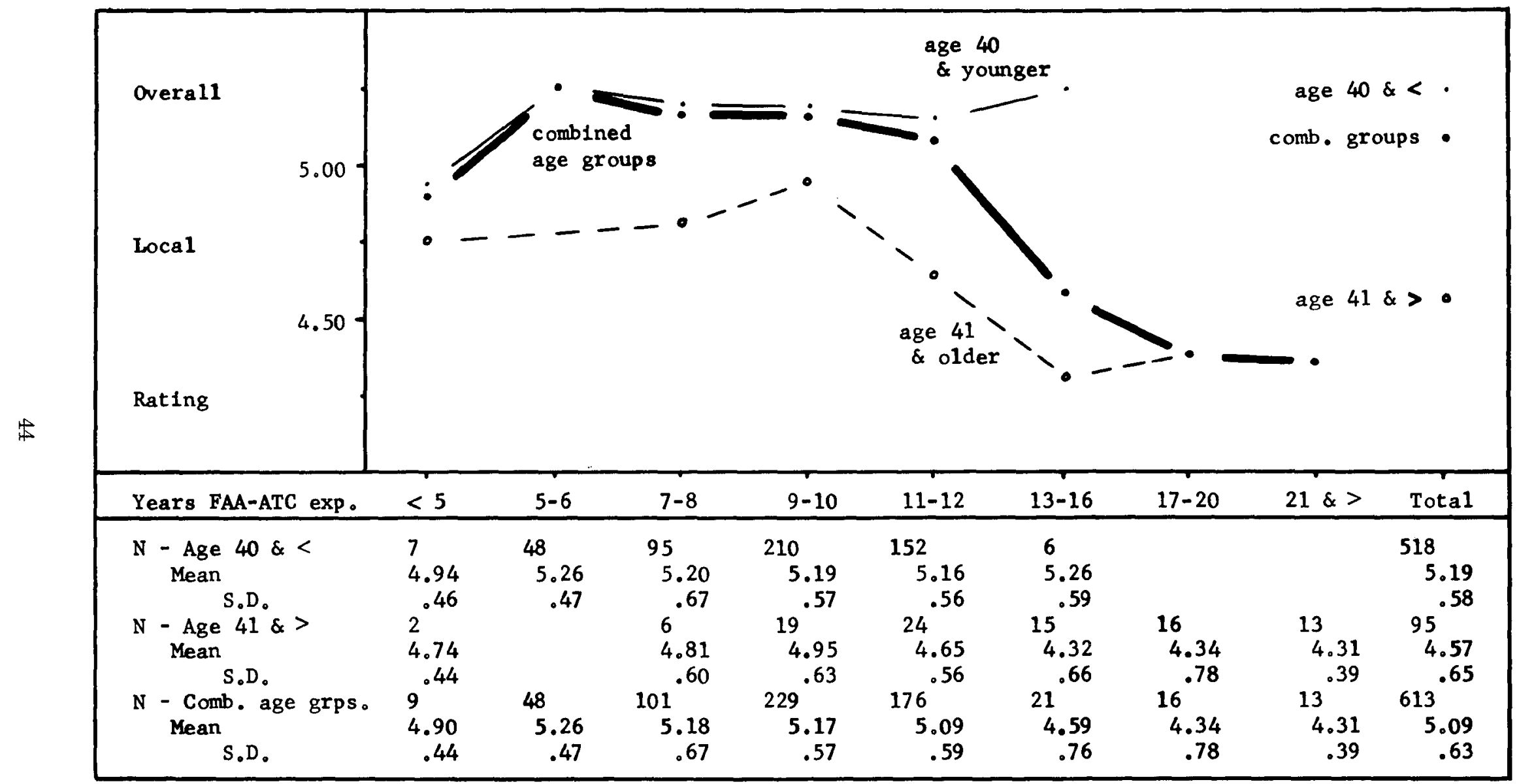

*In comparing the mean ratings of the experience groups, irrespective of age, differences are significant ( $\mathrm{p}<.05)$ for: ATCSs having either $5-6,7-8$, or $9-10$ years experience versus those having either 13-16, 17-20, or 21 or more years and ATCSs having 11-12 years experience versus those having 17-20 or 21 or more years. For age subgroups within tenure levels, significant differences pertain to ATCSs with 11-12 and 13-16 years experience. 
Appendix 15. Means* of Overall General Ratings by age level for Terminal ATCSs of dichotomized FAA ATC experience groups "12 years or less" and "13 years or more."

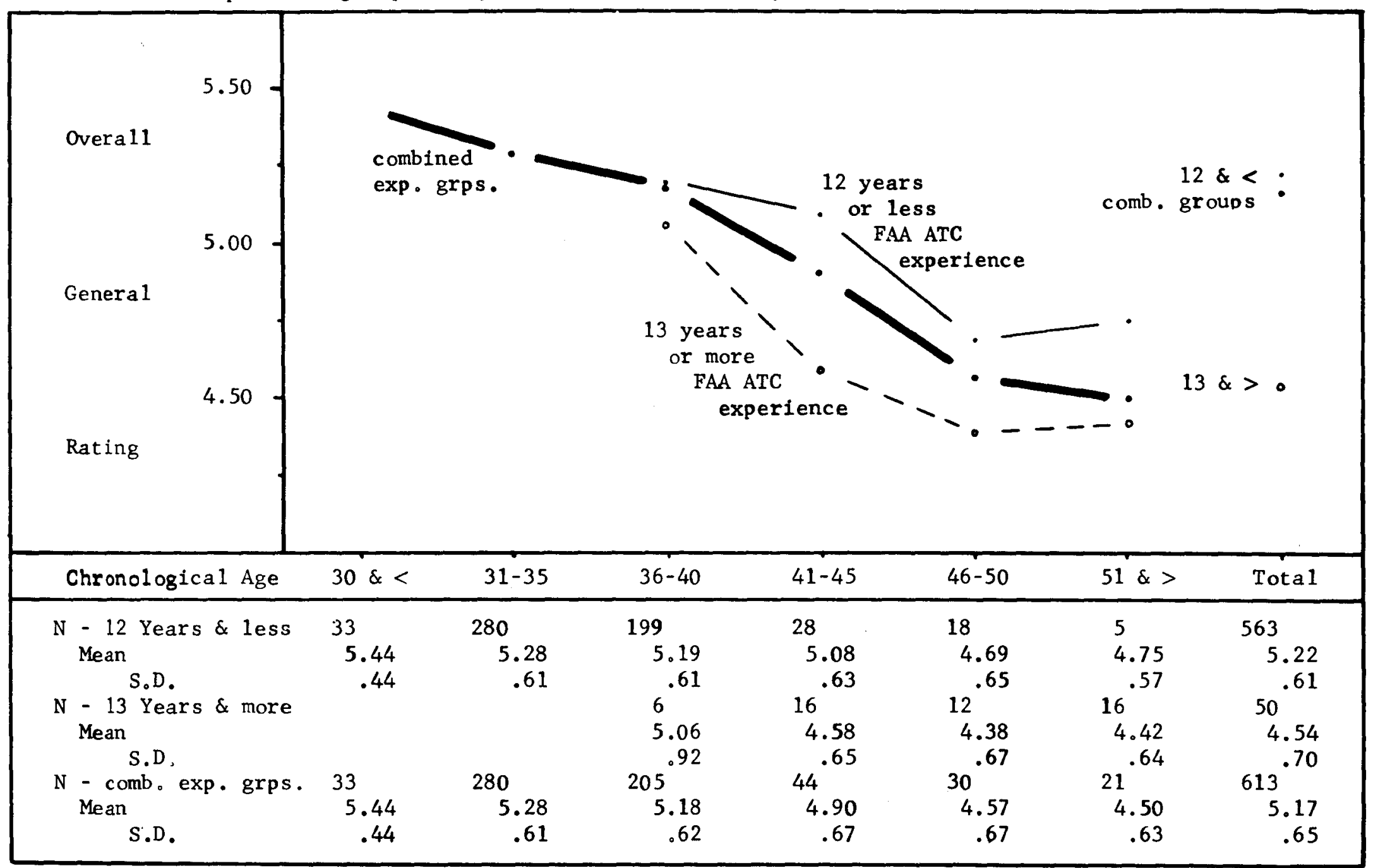

*Disregarding experience, differences between the mean ratings of each of the following groups are significant ( $\mathrm{p}<.05)$ : ATCSs of either age 30 and younger or $31-35$ versus those either 41-45, 46-50, or 51 and older and those of age 36-40 versus those either 46-50 or 51 and older. Of the differences between experience subgroups within age levels, only that pertaining to ATCSs of age 41-45 is significant. 
Appendix 16. Means* of Overall General Ratings by FAA ATC experience level for Terminal ATCSs of dichotomized age groups "40 and younger" and "41 and older."

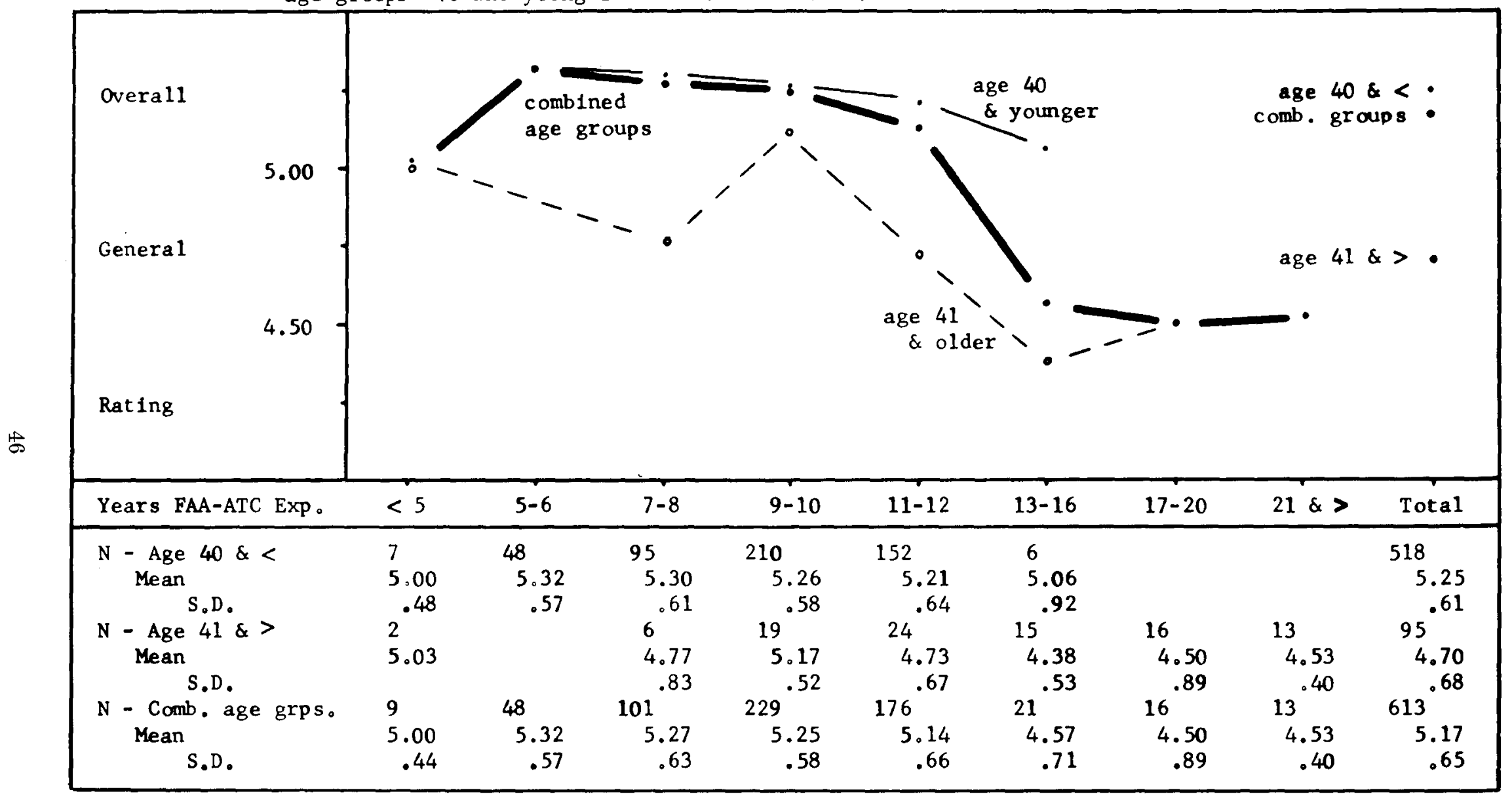

*In comparing the mean ratings of the experience groups, irrespective of age, differences are significant $(\mathrm{p}<.05)$ for: ArCSs having either $5-6,7-8$, or $9-10$ years experience versus those having either 13-16, 17-20, or 21 or more years and ATCSs having 11-12 years experience versus those having either 13-16 or 17-20 years. For age subgroups within tenure leve1s, significant differences pertain to ATCSs with 7-8 and 11-12 years experience. 
Appendix 17. Means* of Overall Relative Profictency Ratings by age level for Terminal ATcSs of dichotomized FAA ATC experience groups "12 years or 1 ess" and " 13 years or more."

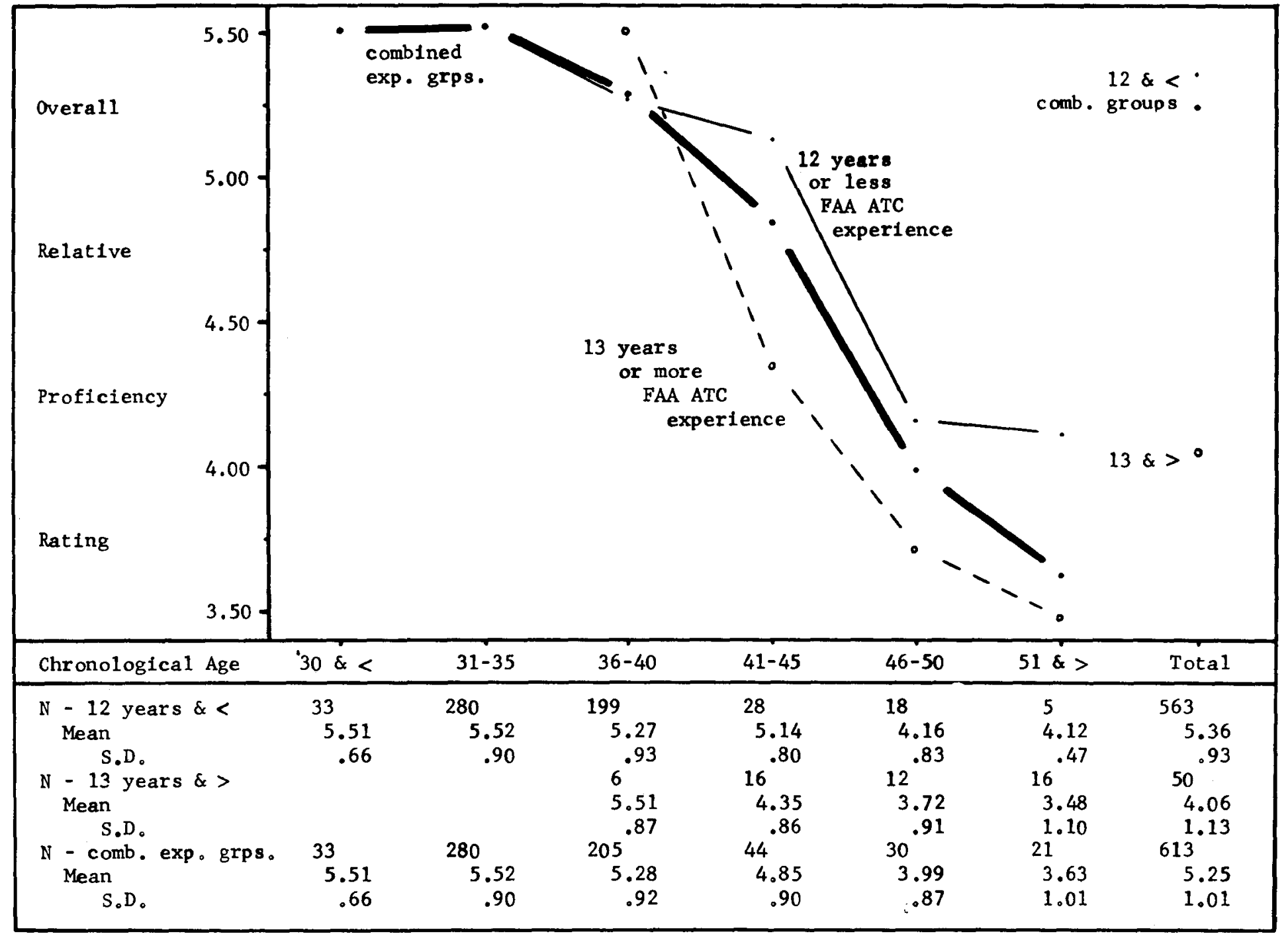

*Disregarding experience, differences between the mear ratings of each of the following groups are significant ( $\mathrm{p}<.05)$ : ATCSs of either age 30 and younger, 36-40, or 41-45 versus those either 46-50 or 51 and older and ATCSs of age 31-35 versus those either 41-45, 46-50, or 51 and older. of the differences between experience subgroups within age levels, only that pertaining to ATCSs of age 41-45 is significant. 
Appendix 18. Means* of Overa11 Relative Proficiency Ratings by FAA ATC experience level for Terminal ATCSs dichotomized age groups "40 and younger" and "41 and older."

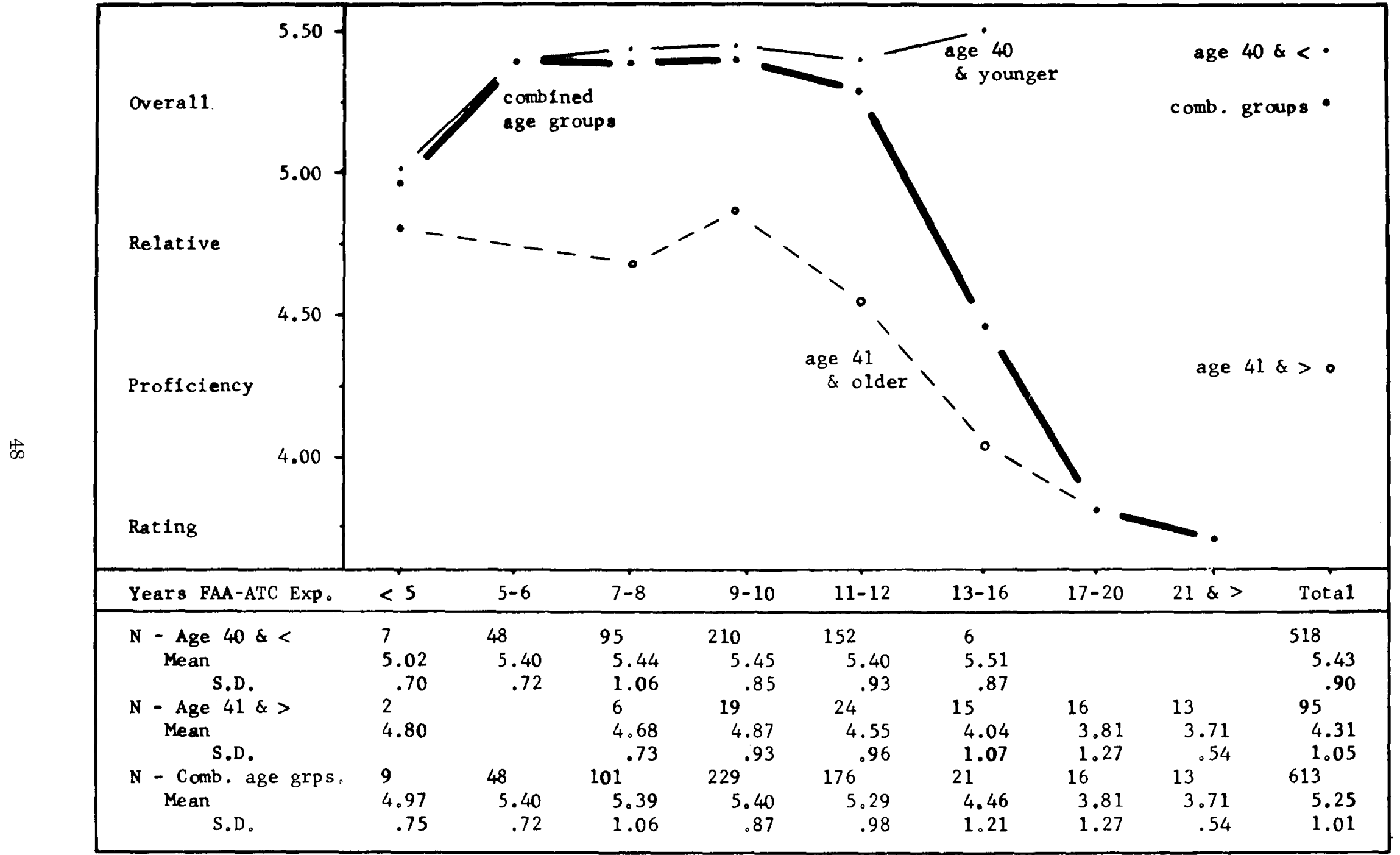

*In comparing the mean ratings of the experience groups, irrespective of age, differences are significant ( $\mathrm{p}<.05)$ for: ATCSs having either 5-6, 7-8, 9-10, or 11-12 years experience versus those having either 13-16, 17-20, or 21 or more years. For age subgroups within tenure levels, significant differences pertain to ATCSs with $9-10.11-12$, and $13-16$ years experience. 
